\title{
Severity, Duration, and Magnitude Regionalization of Standardized Precipitation Index Over Iran During 1993-2016
}

Farshad Fathian ( $\sim$ farshad.fathian@hotmail.com )

Rafsanjan University of Vali Asr https://orcid.org/0000-0001-8205-3787

Zohreh Dehghan

Isfahan University of Technology

Babak Vaheddoost

Bursa Technical University

\section{Research Article}

Keywords: Cluster analysis, drought severity-duration-magnitude, L-moments, risk assessment, standardized precipitation index

Posted Date: September 7th, 2021

DOl: https://doi.org/10.21203/rs.3.rs-791764/v1

License: (9) This work is licensed under a Creative Commons Attribution 4.0 International License. Read Full License 


\section{Severity, Duration, and Magnitude Regionalization of Standardized Precipitation Index over Iran During 1993-2016}

\footnotetext{
Farshad Fathian $^{1 *}$, Zohreh Dehghan ${ }^{2}$, Babak Vaheddoost ${ }^{3}$

*- Corresponding Author: Dr. Farshad Fathian

${ }^{1}$ Department of Water Science \& Engineering, Vali-e-Asr University of Rafsanjan, PO Box: 77188-97111, Rafsanjan, Iran. ORCID: 0000-0001-8205-3787.

${ }^{2}$ Department of Water Engineering, Isfahan University of Technology, PO Box: 84156-83111, Isfahan, Iran. ORCID: 0000-0001-7023-4169.

${ }^{3}$ Department of Civil Engineering, Bursa Technical University. 152 Evler Mahallesi Eğitim Caddesi No: 8516330 Yildirim/BURSA, Turkey. ORCID: 0000-0002-4767-6660.

*- Corresponding Author: Dr. Farshad Fathian; E-mail: f.fathian@vru.ac.ir
} 


\section{Acknowledgments}

The authors acknowledge the Meteorological Organization of Iran, and Vali-e-Asr University of Rafsanjan for providing data.

\section{Declarations}

Funding: No funding was received for conducting this study.

\section{Conflicts of interest/Competing interests: None}

Availability of data and material: The data used are not publicly available due to policy of Iran Meteorological Organization.

Code availability: The R software was used for coding and obtaining the outputs.

Authors' contributions: All authors contributed to the study conception and design. Material preparation, data collection, and analysis were performed by all authors. The first draft of the manuscript was written by Farshad Fathian and all authors commented on previous versions of the manuscript. All authors read and approved the final manuscript.

Ethics approval: Authors confirm that all the ethical issues are fufilled.

Consent to participate: Not applicable.

Consent for publication: Authors declare that they willingly want to publish the manuscript. 


\section{Abstract}

2 Drought is a natural phenomenon that has environmental and socio-economical drawbacks.

3 Especially in arid and semi-arid regions, human activities are closely linked to the water supply

4 and agricultural water use. Although the consequences of drought are prolonged, immediate

5 actions are needed in practice which urges the continuous need for drought monitoring. The

6 present study addresses a regional frequency analysis (RFA) for extreme drought events

7 including severity, duration, and magnitude over Iran. Standardized precipitation index (SPI)

8 time series with 1, 3, 6, 9, and 12 moving averages are determined from 106 meteorological

9 stations for the period 1993-2016. Using Ward's clustering analysis, the drought characteristics

10 are grouped into different clusters and their homogeneity is confirmed by the heterogeneity

11 measure test based on the L-moment approach. The results of RFA indicate that both

12 generalized Pareto (GP) and Pearson type 3 (PE3) distribution functions are the best-fitted regional models to the most identified homogenous clusters of all three drought characteristics, by which the quantiles of each drought characteristic related to different return periods, $\mathrm{T}=2$, $5,10,25,50,75$, and 100 years, are estimated. The spatial pattern of the drought characteristics for all SPI time scales shows that extreme droughts in terms of severity, duration, and magnitude may occur everywhere in the country regardless of local climate conditions. As such, even humid and rainy regions including northern, northwestern, and western parts of Iran that receive high annual precipitation would encounter extreme and severe drought characteristics. It is concluded that the drought risks in the region are mostly the outcome of mismanagement, 21 water resource allocation, and agricultural water use but could be exacerbated due to climatic 22 events.

23 Keywords: Cluster analysis, drought severity-duration-magnitude, L-moments, risk assessment, standardized precipitation index. 


\section{Introduction}

Drought is one of the natural and complex climatic phenomena that have an extensive local and regional effect. The consequences of this recurrent extreme climate event can endanger the social, environmental, and economic activities of a region (Santos et al. 2011; Yenigun and Ibrahim 2019). There is no unique definition of drought on a global scale since the perception and assumptions over the water deficit are different at the regional scale (Tallaksen and Van Lanen 2004). Generally, drought occurs when water availability in a region is lower than the expected normal conditions, and water shortage takes place in time and space (Correia et al. 1991). Droughts can occur everywhere and at any time (e.g. spring, summer, winter); while they are known as the widespread and long-term events of which affect the regional activities very often (Tallaksen and Van Lanen 2004).

There are different types of drought, namely meteorological, agricultural, hydrological, and social-economic droughts (Yenigun and Ibrahim 2019; Yihdego et al. 2019). According to Yihdego et al. (2019), ecological droughts also exist and can be interpreted as a prolonged and widespread deficit in naturally available water supplies which threatens the integrity and sufficiency of the biota. Expectedly, spatial and temporal characteristics of drought are incapable of great influence on different sectors, e.g. agriculture, domestic, forestry, ecology, and industry (Vicente-Serrano et al. 2012). For this, understanding the characteristics of drought and its frequency of occurrence can be used in socio-economic planning. Since the assessment of the possible drought is important in management practices (Potop 2011; Wang et al. 2014); many studies have addressed the issue using performance assessment (e.g. Yu et al. 2014; Cammalleri et al. 2016; Tirivarombo et al. 2018; Danandeh Mehr and Vaheddoost 2020), investigation of the drought characteristics such as severity, duration, and magnitude (e.g. Yu et al. 2013; Lee et al. 2013; Wang et al. 2014; Vaheddoost and Safari 2021), drought risk assessment (e.g. Nam et al. 2015; Van Loon et al. 2015; Xu et al. 2015), and predicting drought 
using machine learning (e.g. Sheffield et al. 2014; Mallya et al. 2016; Papadopoulos et al. 2019; Achour et al. 2020; Danandeh Mehr et al. 2020).

One way to mitigate the drought hazard is to assess the readiness to use drought indices with respect to different time spans. To this end, a range of indices is suggested for further application (e.g. Pedro-Monzonís et al. 2015; Yenigun and Ibrahim 2019), while severity, duration, magnitude, spatial extent, and frequency are found to be the most important characteristics of droughts to illustrate the ongoing situation (Tsakiris et al. 2007). Standardized precipitation index (SPI; McKee et al. 1993), is the most known drought index that evaluates the meteorological drought. But when a moving average operator is used, prolonged SPI indices can also indicate the situation of the agricultural and hydrological droughts in the region. When SPI is used, initially the precipitation time series is transferred to a standardized probability distribution function such that, zero-values represent the median precipitation, and the negative and positive values respectively indicate dry and wet periods during the study period. Readers may also refer to Edward and McKee (1997) and Guttman $(1998,1999)$ for more information about the applications in the SPI.

Since the outputs of drought analysis at a single site are incapable of comparability, several selected stations should be used for regional analysis. Besides, drought is a regional phenomenon while its implementation urges for in situ and discrete analysis (Tallaksen et al. 2000; Espinosa et al. 2019). What's more, the different drought characteristics may be interpreted as the changes in the terrain or the morphology of the nearby stations. If so, regionalization and frequency analysis of drought should be applied in maintaining accurate and reliable drought risk assessment (Vicente-Serrano et al. 2010; Zhang et al. 2012). Furthermore, climatic differences alter the characteristics of drought; and consequently, regional droughts depend either on the climate variability or the micro-climate of the study area (Ali et al. 2019). To this end, spatiotemporal variability is used as an important tool in drought 
clustering. Hence, regionalization of the analysis provides ground for risk assessment, prediction, and monitoring of drought characteristics together with a homogenous drought analysis (Ghadami et al. 2020).

Introduced by Hosking and Wallis (1997), cluster analysis is one of the most common regionalization methods that is based on the spatial attributes of discrete locations (stations). For this, many studies have been conducted to identify homogenous regions of which have temporal similarities in drought indices while considering various clustering techniques (e.g. Mirakbari et al. 2010; Goyal and Sharma 2016; Ayantobo et al. 2018; Mohammadi et al. 2020). Then, additional information can be acquired by conducting a regional frequency analysis on the characteristics of the clusters.

Like many countries, Iran is a vast country $\left(1,648,195 \mathrm{~km}^{2}\right)$ with high climate variability and diverse terrain. For this, irregular precipitation patterns emerge that can be observed either as high or low precipitation events with different characteristics (Ghadami et al. 2020). Recently, Iran has experienced several drought events, that were addressed by many studies. For instance, studies conducted by Amirataee et al. (2018), Bazrafshan et al. (2020), Ghafori et al. (2020), and Nickravesh et al. (2020) have been carried out either for several regions of Iran or with respect to the low amount of stations, while only the drought severity during a specific time frame is addressed. However, extensive analysis with respect to spatiotemporal characteristics of drought at different time scales has not been conceded across Iran. But, the regionalization and the frequency analysis of droughts throughout Iran are necessary to achieve accurate and reliable results in agricultural uses, water allocation, disaster management, and providing appropriate and effective solutions.

Given such drawbacks in previous studies, this study aims to $(i)$ cluster the severity, duration, and magnitude of drought for the SPI index at 1,3,6, 9, and 12-time scales for homogenous regions using a high-density database (106 meteorological stations) based on Ward clustering 
method, (ii) apply regional frequency analysis for each of spatial characteristics of SPI drought based on the L-moment approach. Likewise, the L-moment, as one of the common methods in regional frequency analysis of the drought characteristics, is used along with the identification of homogeneous regions, testing regional frequency distributions, and quantile estimation (Rajsekhar et al. 2013; Domínguez-Castro et al. 2019; Tian and Quiring 2019). In other words,

106 the L-moment method is coupled with the cluster analysis technique for the regionalization of 107 the drought characteristics, identification of extreme drought events, and estimation of extreme 108 drought quantiles across Iran. The results of this research would increase the awareness against 109 the drought characteristics and mitigation of drought hazards in improving the management and 110 planning of water resources and agricultural activities in different regions of Iran.

\section{2. Materials and Methods}

113 2.1. Study area and data

114 Iran is a country that is located in western Asia $\left(25^{\circ}-40^{\circ} \mathrm{N}\right.$ latitudes; $45^{\circ}-65^{\circ} \mathrm{E}$ longitudes $)$. It 115 has predominantly arid and semi-arid climates which is a drawback of being located in the 116 subtropical high-pressure belt. But, the spatial distribution of precipitation due to the noticeable

117 effects of Alborz and Zagros mountain ranges in northern and western Iran is different. For this, 118 the precipitation patterns in Iran are irregular (i.e. have large verity) and are under the influence 119 of different atmospheric systems such that the long-term mean annual precipitation varies from 120 less than $50 \mathrm{~mm}$ (in the southeast) to more than $1000 \mathrm{~mm}$ (in the north; Ghadami et al. 2020).

121 Hence the north, northwest, southwest, and southeast of the country are respectively under the 122 influence of the Caspian Sea, Mediterranean, Monsoonal, and Indian Ocean-Oman Sea systems 123 (Modarres 2006; Nouri and Homaee 2020). Moreover, due to the interplay between the sea and

124 the regional terrain, annual precipitation in the southern Caspian Sea might reach up to 2000 $125 \mathrm{~mm} /$ year in coastlines along with a narrow strip. Likewise, Iran's relatively low mean annual 
126 precipitation $(250 \mathrm{~mm})$, is considered as one-third of the world average, while it is exacerbated

127 by the harsh geographical conditions and inconsistent temporal distribution of precipitation 128 leading to water deficit (Ghadami et al. 2020).

129 For this, monthly precipitation time series data recorded at 106 meteorological stations between 130 1993-2016 are acquired from Iran Meteorological Organization (www.irimo.ir). Afterward, the 131 time series is used to determine the standardized precipitation index (SPI) with 1, 3, 6, 9, and 13212 moving averages (i.e. SPI-1, SPI-3, SPI-6, SPI-9, and SPI-12) are used in evaluating the 133 meteorological, agricultural, and hydrological droughts in the region. Figure 1 shows the

134 geographical location and spatial distribution of the rain gauge stations across Iran. Table 1 also 135 presents the list of the meteorological stations and their geographical properties. It is noteworthy 136 that the numbers given next to the station (green circle) in Figure 1, designates the number of 137 the station detailed in Table 1.

\section{Figure 1}

\section{Table 1}

\subsection{Standardized precipitation index (SPI)}

The SPI is a widely used index in monitoring and analyzing droughts based on precipitation data with different time scales (Keyantash 2018). It was first introduced by McKee (1993) and is simply obtained based on fitting data to a gamma distribution, and then transformed to a

146 normal distribution (Aksoy 2000). The SPI is closely related to agricultural activities on short

147 time scales (i.e. 3 and 6 months), while the SPI is associated with water resources management 148 and planning at longer time scales (i.e. 9 and 12 months). The SPI values for each time scale 149 can be calculated as follows:

$$
S P I_{i j}=\frac{x_{i j}-\mu_{j}}{\sigma_{j}}
$$


150

151

152

153

154

155

156

$$
W=\sum_{j=1}^{k}\left(\sum_{i=1}^{n_{j}} d_{i j}^{2}\right)
$$

\section{Figure 2}

\subsection{Clustering method}

Ward's method is broadly applied in the hierarchical cluster analysis technique for clustering the hydroclimatic data (Dehghan et al. 2018). In this respect, homogenous clusters are characterized by minimizing the inter-cluster variance; and at each step, two clusters with a minimum Euclidean distance from the allocated centroids are pooled towards each other. Then, the following equation is used as Ward's statistics (Ward 1963):

169 where $W$ is Ward's statistics, $d_{i j}$ is the Euclidean distance between attributes at stations $i$ and

$170 j$ in the region (Waseem et al. 2016). Interested readers may refer to Dehghan et al. (2018) and 171 cited articles by the study for more details. 
174 After which the clustering analysis is conducted for the drought characteristics, the RFA is 175 applied on the identified clusters of $S, D$, and $M$. For this, the methodology suggested by 176 Hosking and Wallis (1997) based on the L-moments is used. It has four principal stages which 177 are briefly given as below.

178 (i) First, evaluate the homogeneity of each cluster, identified by the clustering method for each 179 drought characteristic. For this, the $H_{k} \cdot k=1.2 .3$ heterogeneity measure is used to identify 180 whether each cluster is a homogenous region. For this, the $H_{k} \cdot k=1.2 .3$ heterogeneity measure 181 is used to identify whether each cluster is a homogenous region or not. If $H_{1}<1,1 \leq H_{1}<2$, 182 or $H_{1} \geq 2$, then it can respectively conclude that the cluster is "acceptably homogenous", 183 "relatively homogenous", or "definitely heterogeneous". It is noteworthy that the numerical 184 limits for $H_{2}$ and $H_{3}$ measures are similar to those of $H_{1}$ given above.

185 (ii) Then, the best fit regional probability distribution function is determined. For this, L186 moment ratio diagrams (L-kurtosis against L-skewness) and a goodness-of-fit test ( $Z$ statistic) 187 are used to select the best regional fitted distribution. Five distribution functions with three188 parameter, e.g. generalized normal (GNO), generalized extreme value (GEV), generalized logistic (GLO), generalized Pareto (GP), and Pearson type 3 (PE3), are used to conduct the RFA. By drawing the L-kurtosis (L-Ck) against L-skewness (L-Cs), the theoretical L-moment 191 ratio curves of the distribution fictions can be compared with the scatterplot of the data.

192 Afterward, the best fit distribution function based on the sample average and the best fit line is selected. Likewise, by using the goodness-of-fit, $Z$ statistic (Hosking and Wallis 1993) for the tested distributions can be accepted if $|Z| \leq 1.64$ with a 0.10 significance level; while the best-

195 fit model is the distribution with the lowest $|Z|$. In case, a four-parameter Wakeby (WAK)

196 distribution function is applied to station frequency analysis when none of the distribution with 197 three-parameter could satisfy the $|Z| \leq 1.64$ criterion (Hosking and Wallis 1997). 
(iii) Afterward, distribution quantiles are estimated for different return periods of each drought characteristic based on regional frequency relationships at each gauged and/or ungauged site of each cluster. For this, the parameters of the best-fitted distribution function associated with each cluster are estimated based on the regional L-moment technique. Then, the quantiles of $S, D$, and $M$ characteristics with 2-, 5-, 10-, 25-, 50-, 75-, and 100-year return periods are estimated as the regional quantiles. Eventually, the quantiles of each station in the intended cluster are 204 calculated as,

$$
Q_{i}(F)=\lambda_{1}^{(i)} q(F)
$$

205 where $Q_{i}(F)$ and $\lambda_{1}^{(i)}$ are station quantiles and the L-moment of order 1 at station $i$; and $q(F)$ 206 is the regional quantiles with the probability of non-exceedance of $F$.

207 (iv) Finally, to assess the performance of the RFA of the best-fitted distributions to homogenous 208 clusters, the relative root mean square error (rRMSE) is used for each station, $i$, with return 209 period $T$ as follows (Gaal et al. 2008a).

$$
r R M S E=\frac{1}{N} \sum_{i=1}^{M}\left[\frac{1}{M} \sum_{m=1}^{M}\left(\frac{x_{i . m}^{T}-x_{i}^{T}}{x_{i}^{T}}\right)^{2}\right]^{1 / 2}
$$

210 where $x_{i . m}^{T}$ is the estimated value in the $m^{\text {th }}$ sample of Monte Carlo simulation, $x_{i}^{T}$ is the 211 observed value, $N$ is the number of stations, and $M$ is the number of iteration for the Monte 212 Carlo simulation. The interested reader may refer to Hosking and Wallis (1997), Santos et al.

213 (2011), Fathian and Dehghan (2019) for more details about the terminologies and applications 214 given above. 


\section{Results and Discussion}

220 4.1. Clustering of drought characteristics

221 The optimal number of clusters for each drought characteristic with different SPI time scales 222 based on Ward's clustering technique for the 1993-2016 period is given in Table 2. It is obvious 223 that the optimal number of clusters differs for each of the drought characteristics and SPI time 224 scales; while the optimal number with five clusters has the highest frequency. It is concluded 225 that these results are in agreement with Ghadami et al. (2020) that identified four homogenous 226 regions of drought severity-duration index at SPI-12 over Iran using 56 stations. Furthermore, based on the results of the Bazrafshan et al. (2020), three homogeneous regions of drought in arid and semi-arid areas of Iran can be recognized that confirms the given results of Table 2.

\section{Table 2}

The spatial pattern of drought severity, duration, and magnitude for different time scales are respectively given in Figures 3-5. In the Figures, each of the drought characteristics and the allocated time scale for the selected stations are clustered with different colors and shapes. It is concluded that the stations are mostly located either in the clusters of (i) central, southeastern, and northeastern; (ii) northern coastline; (iii) western and northwestern; or (iv) the southeastern and the southern coastline. Likewise, clusters which are mainly located in the (i)-(iv) parts have warm-dry, moderate-humid, cold-mountainous, and warm-humid climates respectively. As reported by Modarres and Sarhadi (2011), and Amini et al. (2020), these sub-climates are

240 largely corresponding to the geographical characteristics and different precipitation patterns over Iran; and can be recognized as the verification of the clustering results. Additionally, by examining the clusters, geographical location of the stations, and the SPI time series it can be 
concluded that no spatial continuity between the geographical regions exists. Therefore, the

244 droughts associated with any clusters confirm the results of Mojarad et al. (2014).

\section{Figure 3}

\section{Figure 4}

\section{Figure 5}

\subsection{RFA of the drought characteristics}

\subsubsection{Heterogeneity measures}

The homogeneity level associated with the stations of any cluster related to the drought characteristic is separately calculated using the homogeneity measure $H$ test (Hosking and Wallis 1993,1997$)$. Table 3 details the average homogeneity measures $\left(H_{1} \cdot H_{2} \cdot H_{3}\right)$ for the drought characteristics at different SPI time frames. As illustrated, the $H$ measures are less than one, indicating that all defined clusters for each drought characteristic and time scale are considerably homogenous. In other words, the statistical features of any cluster for each drought characteristic are similar. Hence, a regional frequency distribution can be used in modeling the probabilistic behavior of drought characteristics at each homogenous cluster. As given in Table 2, most of the $Z$ statistics are negative, indicating that there is less dispersion among the in situ statistics compared to the homogenous clusters with independent in situ distribution functions.

\subsubsection{Goodness-of-fit Z statistic}

To find the most appropriate regional distribution of drought characteristics for each cluster, the goodness-of-fit $Z$ statistic test is used. For this, the distribution function that has the lowest 
absolute $Z$ statistic, i.e. $|Z| \leq 1.64$, is used as the best-fit distribution for each cluster of each 269 drought characteristic. The $Z$ statistic for the best-fit distribution function of each cluster related to all drought characteristics with different SPI time scales is given in Table 4. This table details

271 the best-fit distribution function such that the GP and PE3 fitted to $S, D$, and $M$ have the most 272 frequency between the allocated SPI scales. The GEV and GNO distributions are also fitted to 273 the clusters of which drought characteristics are related to the northern and northwestern regions 274 of the study area. However, results indicate that the three-parameter distributions are more 275 appropriate for the homogenous clusters. Similarly, Ghadami et al. (2020) showed that the 2-

276 277 parameter log-normal distribution is the most reliable distribution for drought severity-drought index of the 12-month SPI across Iran. Similarly for SPI-3 and SPI-9, i.e. cluster 2 (C2) and cluster 5 (C5) respectively, the WAK distribution is used since Hosking and Wallis's (1997) reported for its applicability when the $Z$ statistic is greater than 1.64 . In this respect, the $Z$ statistic related to the three-parameter distributions fitted to the clusters of the drought characteristics shows that the theoretical L-Ck is well-matched with the regional average L-Ck of the observed data for each cluster and time scale.

\subsubsection{Spatial pattern at different return periods}

After determining the homogenous clusters of the drought severity, duration, and magnitude across the country, the spatial pattern of the estimated in situ $S, D$, and $M$ quantiles corresponding to $2,5,10,25,50,75$, and 100-year return periods are obtained for each SPI time scale.

\section{Table 4}


294 Figures 6-10 demonstrate the spatial patterns of drought $S$ with different return periods 295 throughout Iran for SPI-1, SPI-3, SPI-6, SPI-9, and SPI-12, respectively. Based on the results, 296 in all of SPI time scales return period and severity increased. For instance, in the SPI-1 time 297 series, the $S$ measures varied between 0 to 6 , and 0 to 15.2 respectively for the 2 -and the 100 298 year return periods (Figure 6). The same behavior is observed in the remaining SPI time scales, 299 but the upper and lower limits of $S$ showed differences in practice. To this end, results show 300 that in the SPI-3 (Figure 7), SPI-6 (Figure 8), SPI-9 (Figure 9), and SPI-12 (Figure 10) time 301 scales, the spatial patterns are acceptably uniform. In the SPI-1 time scale (Figure 6), the 302 drought severity for the southern coastal, southwestern, and a small part of the central regions 303 is higher than the remaining parts, with maximum measures of roughly 4.5-15.2 depending on 304 the given return period. In SPI-3 (Figure 7) and SPI-6 (Figure 8) time scales, the highest 305 measures of $S$ are mostly observed in the northern coastal and partly in the northwestern, western, northeastern, and southeastern regions. Therefore, the maximum measures vary roughly between 3.5-4.9 for the 2-year to 7.9-27 for the 100-year return periods. In SPI-9 (Figure 9) and SPI-12 (Figure 10), the higher $S$ measures are covered the most parts of the eastern half of the country and partly in the western region, with maximum values between 1.54.5 for the 2-year and 33.6-47.7 for the 100-year return periods. 
320 The spatial patterns of drought $D$ across the country are illustrated in Figures 11-15 for SPI-1, 321 SPI-3, SPI-6, SPI-9, and SPI-12, respectively, with different return periods. As illustrated in the

322 figures, when the return period increases, the drought duration becomes greater for each SPI.

323 In SPI-1, as an example shown in Figure 11, the $D$ values vary from 1.7-7.6 for the 2-year to 324 3.3-14.5 for the 100-year return periods. The results show that the spatial patterns of $D$ regarding SPI-3 (Figure 12) and SPI-6 (Figure 13) as well as SPI-9 (Figure 14) and SPI-12 (Figure 15) are largely uniform. Figure 11 also shows that the drought $D$ for SPI-1 in the southwestern, southern coastal, and part of the central regions of Iran is higher than the other parts, while maximum values vary between 3.4 and 14.5 at the desired return period. The highest values of $D$ for both SPI-3 (Figure 12) and SPI-6 (Figure 13) are observed in northern coastal, northwestern, and southeastern regions. The maximum values fluctuated between 4.46 corresponding to the 2-year and 12.6-16.2 corresponding to the 100-year return periods. According to SPI-9 (Figure 14) and SPI-12 (Figure 15), higher values of $D$ are observed in the northwestern, northern, and southern coastal regions, and most parts of the eastern half of Iran,

334 with maximum measures from 3.7-8.4 (2-year return period) and 15.8-19.8 (100-year return 335 period). 
345 Figures 16-20 reveal the spatial patterns of drought $M$ respectively for SPI-1, SPI-3, SPI-6, SPI3469 , and SPI-12 with different return periods. All figures show that, for each SPI time scale, the 347 drought magnitude intensifies as the return period increases. For instance by considering the 348 SPI-1, that the $M$ measures respectively changes between 1.5-4.3 to 17.2-47.7 related to the 2349 year and 100-year return periods (Figure 16). The results indicate generally spatial uniform 350 patterns for each SPI time scale. In SPI-1 (Figure 16), the drought magnitude in most parts of the eastern half, the western, and partially in the southern coastal regions is higher than the other regions, while the maximum respectively varies between $3.5-4.3$ to $36.7-47.7$ for the 2year and the 100-year return periods. In SPI-3 (Figure 17), the highest values of $M$ are observed in the northern coastal, most parts of the northwestern, and partly in the southern and southeastern regions. Similarly, the maximum values respectively vary between 4.4-5.1 to 12.515.2 for 2-year and the 100-year return periods. To this end, the highest $M$ values related to SPI-6 (Figure 18) are observed partly in the northeastern and southeastern regions. However, the western half of the country experienced maximum measures between $0.81-0.90$ to $2.29-2.73$ respectively for the 2-year and the 100-year return periods. In SPI-9 (Figure 19), the highest 360 measures of $M$ are covered mainly the western half and small portion of the east and west, with maximum values approximately ranging between $0.73-0.84$ to $2.39-2.86$ respectively for the 2year and the 100-year return periods. In SPI-12 (Figure 20), the highest $M$ values are observed in the northern coastal, most parts of the northwestern regions (especially with 2- and 5-year

364 return periods), and some stations located in the eastern half of the country. The maximum 365 measures vary from 0.53-0.64 associated with the 2-year return period to 2.8-3.5 associated 366 with the 100-year one. 


\subsubsection{Performance evaluation at different return periods}

375 The average amounts of rRMSE percentage of the drought characteristics obtained from the RFA associated with SPI-1, -3, -6, -9, and -12 with different return periods are given in Figure 21. In all of the SPIs with $\mathrm{T}=5$ years onwards, the estimation error associated with the severity, duration, and magnitude showed increases when the return period increases. Additionally, depending on the type of SPI, the performance of the RFA of the best-fit distributions to the homogenous clusters (i.e., the relative error values) for each drought characteristic varied for all return periods. In the case of SPI-1, the estimation error associated with magnitude was greater than the remaining two drought characteristics for the given return periods. However, in both SPI-3 and SPI-9, the error percentage associated with severity is higher than the other drought characteristics, while in both SPI-6 and SPI-12, the error value related to duration was higher than the remaining values.

\section{Figure 21}

\section{Conclusions}

390 The aim of the present study is to evaluate the risk of drought across Iran based on frequency

391 analysis of the drought severity, duration, and magnitude associated with the SPI-1, -3, -6, -9,

392 and -12 time scales for the first time. By now, no study has evaluated the whole country (Iran) 393 using such a big data inventory (i.e., 106 gauge stations) to analyze the regional frequency of 
394 drought characteristics with different time scales (i.e., SPIs). To this end, from the results of the

395 cluster analysis in three drought characteristics can be understood that most of the homogeneous

396 regions are formed completely cohesive and dense nationwide within the selected time scales.

397 According to the same results, the homogeneous regions obtained by the heterogeneity test and

398 the clusters identified for each drought characteristic for every time scale were found to be

399 homogenous and associated with measure $\mathrm{H}_{1}$.

400 The results of the RFA technique also suggested that both of the GP and PE3 distribution 401 functions show satisfactory results to be the best-fit models for the severity, duration, and 402 magnitude for various SPI with different time scales. However, the Wakeby distribution 403 function was found to be the better match for SPI-3 and SPI-9 in clustering the magnitude of 404 drought due to having a higher $Z$ statistic $(Z>1.64)$.

405 The spatial pattern analysis of all drought characteristics also demonstrated that, depending on 406 the time scale of SPI, extreme droughts in terms of severity, duration, and magnitude can occur everywhere regardless of regional climate conditions. In other words, even in northern Iran with

408 a humid climate that receives the highest amount of precipitation, severe drought events have 409 occurred in recent years. Thereby, it can be concluded that every part of Iran, particularly the 410 northwestern and southeastern regions with respect to $S$; the northwestern and most parts of the 411 eastern half of the country with respect to $D$; and the southeastern and most parts of the western

412 half of the country with respect to $M$, are exposed to higher drought characteristics during 1993413 2016. Hence, this condition should be recognized as an early warning to Iranian water resources 414 planners and managers that exceptionally severe drought occurrences have a tendency to affect 415 the entire country, causing significant damage and losses. This means that if both severe 416 droughts frequently take place and mismanagement of the water supplies continues, problems 417 related to the water sector would escalate to irreversible situations, capable of affecting the 418 socio-economic conditions in the country. 


\section{References}

420 Achour K, Meddi M, Zeroual A, Bouabdelli S, Maccioni P, Moramarco T (2020) Spatiotemporal analysis and forecasting of drought in the plains of northwestern Algeria using the standardized precipitation index. Journal of Earth System Science 129(1): 1-22.

Aksoy H (2000) Use of gamma distribution in hydrological analysis. Turkish Journal of Engineering and Environmental Sciences 24(6): 419-428.

Ali Z, Hussain I, Faisal M, Shoukry AM, Gani S, Ahmad I (2019) A framework to identify homogeneous drought characterization regions. Theoretical and Applied Climatology 137(3-4): 3161-3172.

Amini M, Ghadami M, Fathian F, Modarres R (2020) Teleconnections between oceanicatmospheric indices and drought over Iran using quantile regressions. Hydrological

Amirataee B, Montaseri M, Rezaie H (2018) Regional analysis and derivation of copula-based drought Severity-Area-Frequency curve in Lake Urmia basin, Iran. Journal of Environmental Management 206: 134-144.

Ayantobo OO, Li Y, Song S (2018) Multivariate drought frequency analysis using four-variate symmetric and asymmetric Archimedean copula functions. Water Resour. Manag. 33: 103127.

Bazrafshan O, Zamani H, Shekari M (2020) A copula-based index for drought analysis in arid and semi-arid regions of Iran. Natural Resource Modeling 33(1): e12237.

Cammalleri C, Micale F, Vogt J (2016) A novel soil moisture-based drought severity index (DSI) combining water deficit magnitude and frequency. Hydrological Processes 30(2):

442 Cavus Y, Aksoy H (2019) Spatial drought characterization for Seyhan River basin in the 443 Mediterranean region of Turkey. Water 11(7): 1331. 
444 Correia FN, Santos MA, Rodrigues RR (1991) Reliability in regional drought studies. In Water

445 Resources Engineering Risk Assessment (pp. 43-62). Springer, Berlin, Heidelberg.

446 Danandeh Mehr A, Vaheddoost B (2020) Identification of the Trends Associated with the SPI 447 and SPEI Indices across Ankara, Turkey. Theoretical and Applied Climatology 139: 1531$448 \quad 1542$.

449 Danandeh Mehr A, Vaheddoost B, Mohammadi B (2020) ENN-SA: A novel neuro-annealing $450 \quad$ model for multi-station drought prediction. Computers \& Geosciences 145: 104622.

451 Dehghan Z, Eslamian SS, Modarres R (2018) Spatial clustering of maximum 24-h rainfall over 452 Urmia Lake Basin by new weighting approaches. International Journal of Climatology $453 \quad 38(5): 2298-2313$.

454 Domínguez-Castro F, Vicente-Serrano SM, Tomás-Burguera M, Peña-Gallardo M, Beguería S, 455 Kenawy AE, Luna Y, Morata A (2019) High-spatial-resolution probability maps of drought 456 duration and magnitude across Spain. Natural Hazards and Earth System Sciences 19(3): $457 \quad 611-628$.

458 Edwards DC, McKee TB (1997) Characteristics of 20th century drought in the United States at 459 multiple time scales, Climatology Rep. 97-2, Department of Atmospheric Science, 460 Colorado State University, Fort Collins, Colorado.

461 Espinosa LA, Portela MM, Pontes Filho JD, Studart TMDC, Santos JF, Rodrigues R (2019) 462 Jointly modeling drought characteristics with smoothed regionalized SPI series for a small $463 \quad$ Island. Water 11(12): p.2489.

464 Fathian F, Dehghan Z (2019) Using hybrid weighting-clustering approach for regional 465 frequency analysis of maximum 24-hr rainfall based on climatic, geographical, and 466 statistical attributes. International Journal of Climatology 39(11): 4413-4428.

467 Gaal L, Kysel YJ, Szolgay J (2008a) Region-of-influence approach to a frequency analysis of 468 heavy precipitation in Slovakia. J. Hydrol. Earth Syst. Sci. 12: 825-839. 
Ghadami M, Raziei T, Amini M, Modarres R (2020) Regionalization of drought severityduration index across Iran. Natural Hazards 103(3): 2813-2827.

Ghafori V, Sedghi H, Sharifan RA, Nazemosadat SMJ (2020) Comparison of univariate and bivariate regional frequency analysis of drought (case study: Part of semi-Arid climate of Fars Province). Irrigation Sciences and Engineering 43(2): 139-153.

Goyal MK, Sharma A (2016) A fuzzy c-means approach regionalization for analysis of meteorological drought homogeneous regions in western India. Natural Hazards 84(3): $1831-1847$.

Guttman NB (1998) Comparing the Palmer Drought Index and the standardized precipitation index. J. Am. Water Resour. Assoc. (JAWRA) 34: 113-121.

Guttman NB (1999) Accepting the standardized precipitation index: a calculation algorithm. J. Am. Water Resour. Assoc. (JAWRA) 35(2): 311-322.

Hosking JR, Wallis JR (1993) Some statistics useful in regional frequency analysis. J. Wat. Resour. Res. 29: 271-281.

Hosking JRM, Wallis JR (1997) Regional frequency analysis an approach based on L-moments. Cambridge University Press Cambridge. PP. 224.

Keyantash JNCFARSE (2018) The Climate Data Guide: Standardized Precipitation Index (SPI). National Center for Atmospheric Research Staff (Eds), 8.

Lee JH, Kim CJ (2013) A multimodel assessment of the climate change effect on the drought severity-duration-frequency relationship. Hydrol. Process. 27: 2800-2813.

Mallya G, Mishra V, Niyogi D, Tripathi S, Govindaraju RS (2016) Trends and variability of droughts over the Indian monsoon region. Weather Clim. Ext. 12: 43-68.

McKee TB, Doesken NJ, Kleist J (1993, January). The relationship of drought frequency and duration to time scales. In Proceedings of the 8th Conference on Applied Climatology (Vol. 17, No. 22, pp. 179-183). 
Mirakbari M, Ganji A, Fallah SR (2010) Regional bivariate frequency analysis of meteorological droughts. Journal of Hydrologic Engineering 15(12): 985-1000.

Modarres R (2006) Regional precipitation climates of Iran. J. Hydrol. (NZ) 45: 13-27.

Modarres R, Sarhadi A (2011) Statistically-based regionalization of precipitation climates of Iran. Global Planet Change 75: 67-75.

Mohammadi B, Vaheddoost B, Mehr AD (2020) A spatiotemporal teleconnection study between Peruvian precipitation and oceanic oscillations. Quaternary International 565: 111.

Nam WH, Hayes MJ, Svoboda MD, Tadesse T, Wilhite DA (2015) Drought hazard assessment in the context of climate change for South Korea. Agric. Water Manage 160: 106-117.

Mojarad F, Kheiri R, Nouri Z (2014) Analysis of the frequency of daily droughts in Iran with effective drought index. Applied Research in Geographical Sciences 35: 29-48. (In Persian)

Nikravesh G, Aghababaei M, Nazari-Sharabian M, Karakouzian M (2020) Drought Frequency Analysis Based on the Development of a Two-Variate Standardized Index (RainfallRunoff). Water 12(9): 2599.

Nouri M, Homaee M (2020) Drought trend, frequency and extremity across a wide range of

Papadopoulos C, Spiliotis M, Angelidis P, Papadopoulos B (2019) A hybrid fuzzy frequency factor based methodology for analyzing the hydrological drought. Desalination and Water Treatment 167: 385-397.

Pedro-Monzonís M, Solera A, Ferrer J, Estrela T, Paredes-Arquiola J (2015) A review of water scarcity and drought indexes in water resources planning and management. Journal of Hydrology 527: 482-493.

Potop V (2011) Evolution of drought severity and its impact on corn in the Republic of Moldova. Theoretical and Applied Climatology 105(3-4): 469-483. 
Rajsekhar D, Mishra AK, Singh VP (2013) Regionalization of drought characteristics using an entropy approach. Journal of Hydrologic Engineering 18(7): 870-887.

Santos JF, Portela MM, Pulido-Calvo I (2011) Regional frequency analysis of droughts in Portugal. Water Resources Management 25(14): 3537-3558.

Sheffield J, Wood EF, Chaney N, Guan K, Sadri S, Yuan X, Olang L, Amani A, Ali A, Demuth S, Ogallo L (2014) A drought monitoring and forecasting system for sub-Sahara African water resources and food security. Bulletin of the American Meteorological Society 95(6): $861-882$.

Tallaksen LM, Van Lanen HA (Eds.) (2004) Hydrological drought: processes and estimation methods for streamflow and groundwater (Vol. 48). Elsevier.

Tallaksen LM (2000) Streamflow drought frequency analysis. Drought and Drought Mitigation in Europe. Springer, pp. 103-117.

Tian L, Quiring SM (2019) Spatial and temporal patterns of drought in Oklahoma (1901-2014). International Journal of Climatology 39(7): 3365-3378.

Tirivarombo S, Osupile D, Eliasson P (2018) Drought monitoring and analysis: standardised precipitation evapotranspiration index (SPEI) and standardised precipitation index (SPI). Physics and Chemistry of the Earth, Parts A/B/C 106: 1-10.

Tsakiris G, Pangalou D, Vangelis H (2007) Regional drought assessment based on the Reconnaissance Drought Index (RDI). Water Resour. Manage. 21: 821-833.

Vaheddoost B, Safari MJS (2021) Application of signal processing in tracking meteorological drought in a mountainous region. Pure and Applied Geophysics 178: 1943-1957.

540 Van Loon AF (2015) Hydrological drought explained. Wiley Inter-discip. Rev.: Water 2: 359392.

542 Vicente-Serrano SM, Beguería S, Lorenzo-Lacruz J, Camarero JJ, López-Moreno JI, Azorin543 Molina C, Revuelto J, Morán-Tejeda E, Sanchez-Lorenzo A (2012) Performance of drought 
indices for ecological, agricultural, and hydrological applications. Earth Interactions 16(10): $1-27$.

Vicente-Serrano SM, Beguería S, López-Moreno JI (2010) A multiscalar drought index sensitive to global warming: the standardized precipitation evapotranspiration index. J. Clim. 23: 1696-1718.

Wang Q, Wu J, Lei T, He B, Wu Z, Liu M, Mo X, Geng G, Li X, Zhou H, Liu D (2014) Temporal-spatial characteristics of severe drought events and their impact on agriculture on a global scale. Quaternary International 349: 10-21.

Ward JH (1963) Hierarchical grouping to optimize an objective function. J. Am. Stat. Assoc. 58: $236-244$.

555

Waseem M, Ajmal M, Kim TW (2016) Improving the flow duration curve predictability at ungauged sites using a constrained hydrologic regression technique. KSCE Journal of Civil Engineering 20(7): 3012-3021.

Xu K, Yang D, Xu X, Lei H (2015) Copula based drought frequency analysis considering the spatio-temporal variability in Southwest China. J. Hydrol. 527: 630-640.

Yenigun K, Ibrahim WA (2019) Investigation of drought in the northern Iraq region. Meteorological Applications 26(3): 490-499.

Yihdego Y, Vaheddoost B, Al-Weshah RA (2019) Drought indices and indicators revisited. Arabian Journal of Geosciences 12(3): 69-81.

Yu M, Li Q, Hayes MJ, Svoboda MD, Heim RR (2014) Are droughts becoming more frequent or severe in China based on the standardized precipitation evapotranspiration index: 19512010? Int. J. Climatol. 34(3): 545-558.

Yu W, Shao M, Ren M, Zhou H, Jiang Z, Li D (2013) Analysis on spatial and temporal characteristics drought of Yunnan Province. Acta Ecol. Sin. 33: 317-324. 

droughts across the Pearl River basin, China. Journal of Hydrology 472: 355-366. 
Figures

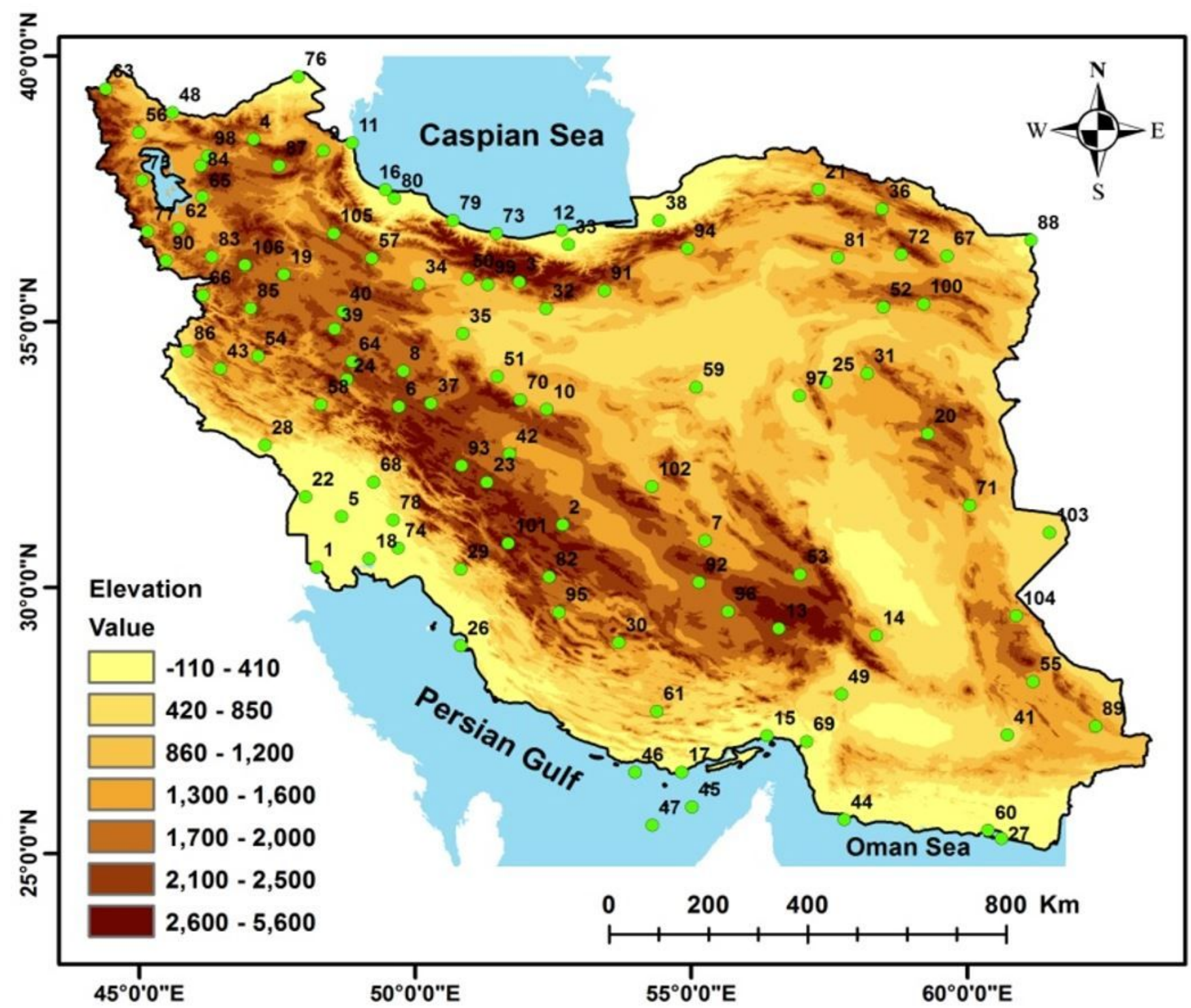

Figure 1

Geographical location of the meteorological stations used in the study 


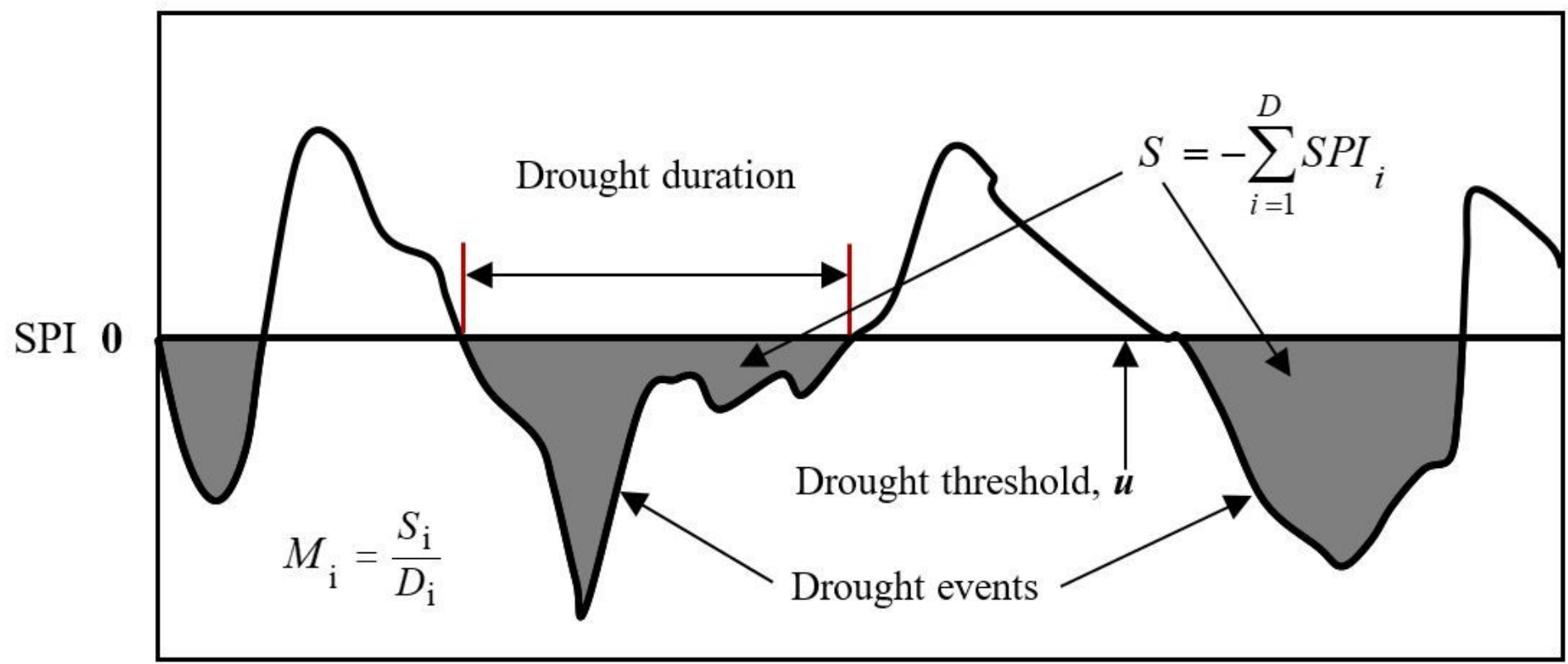

Time (month)

Figure 2

Characteristics of the SPI drought (Source: Santos et al. 2011)
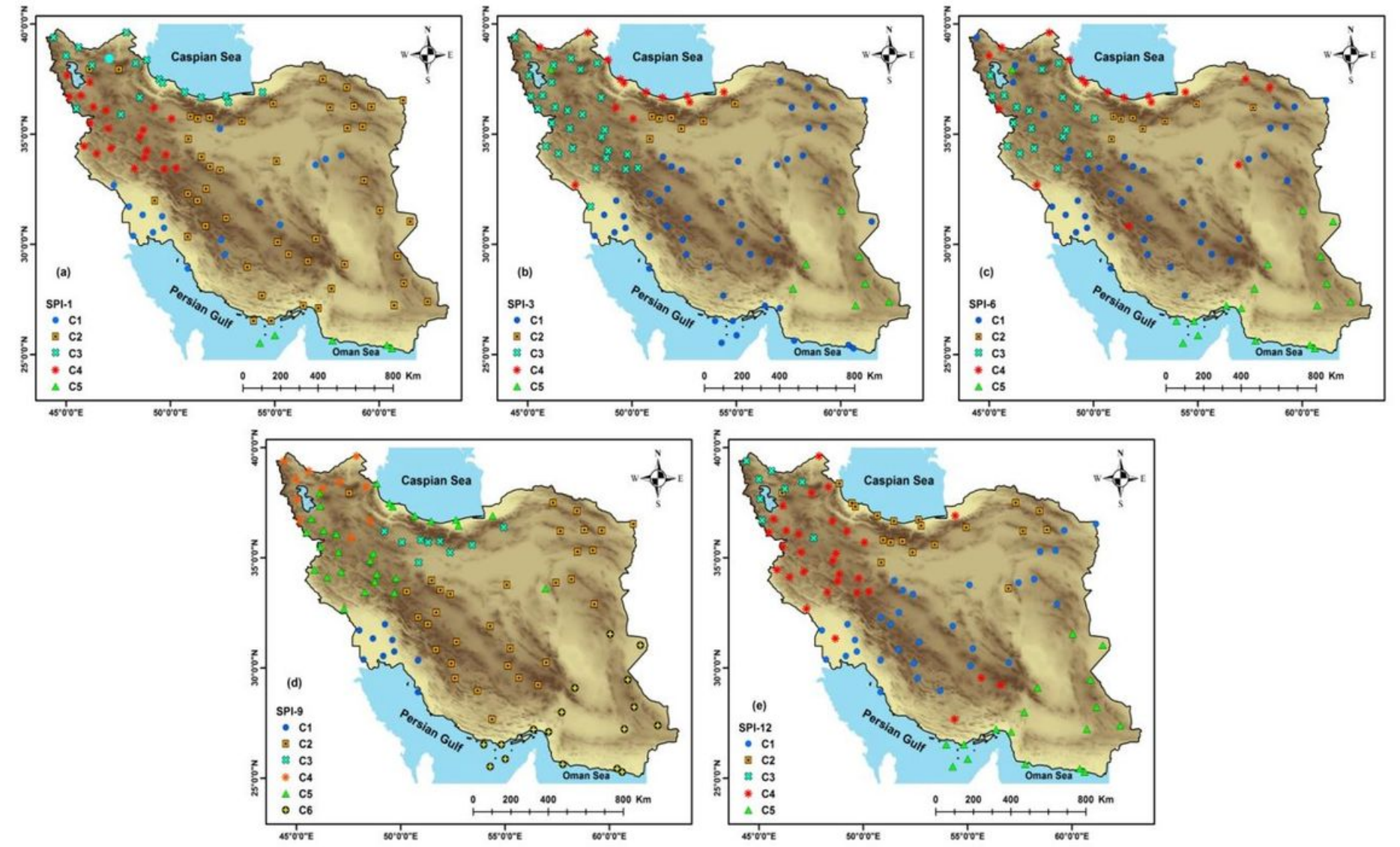

Figure 3 
Spatial pattern of drought severity for (a) SPI-1, (b) SPI-3, (c) SPI-6, (d) SPI-9, (e) SPI-12 across Iran
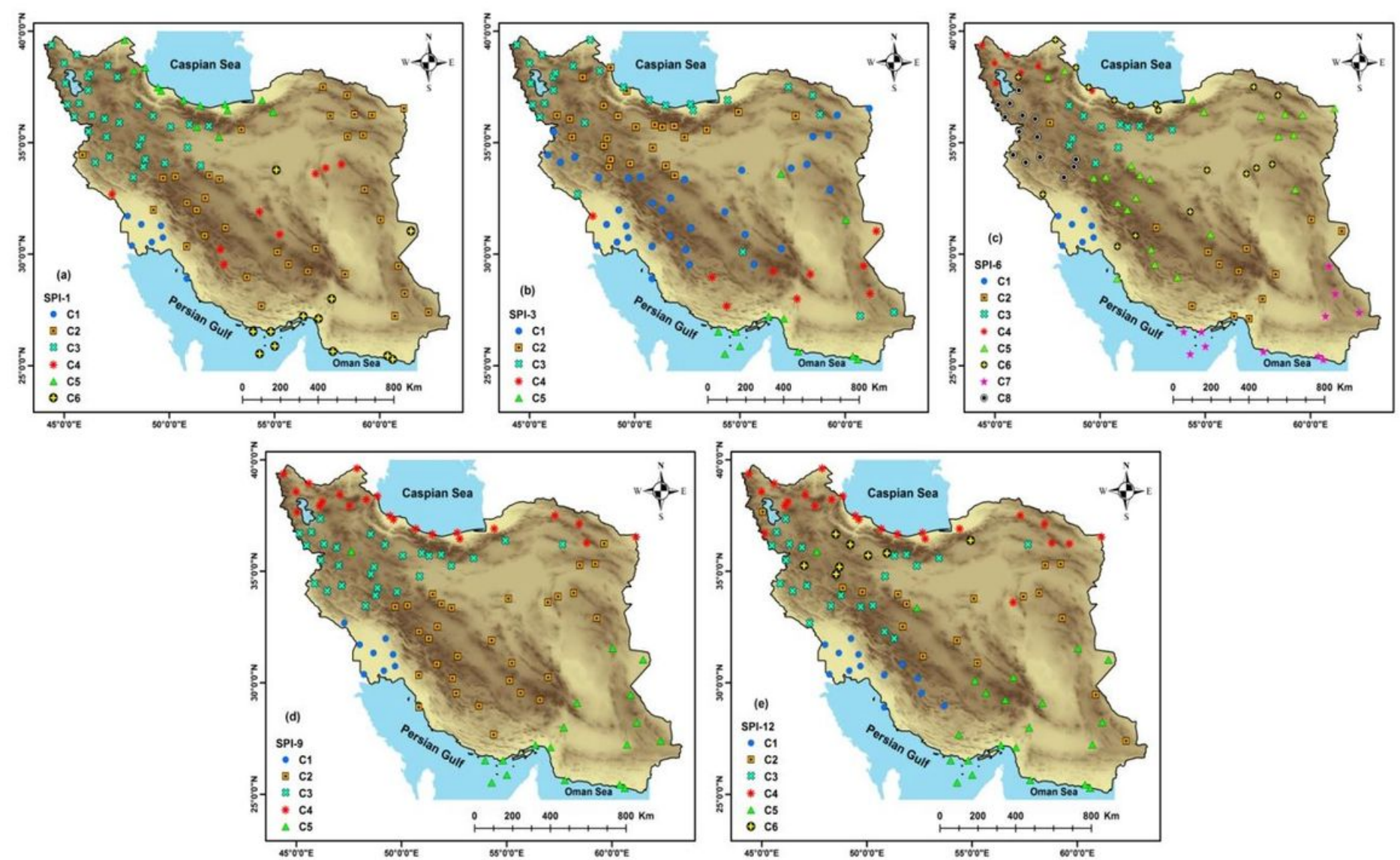

Figure 4

Spatial pattern of drought duration for (a) SPI-1, (b) SPI-3, (c) SPI-6, (d) SPI-9, (e) SPI-12 across Iran

Figure 5

Spatial pattern of drought magnitude for (a) SPI-1, (b) SPI-3, (c) SPI-6, (d) SPI-9, (e) SPI-12 across Iran 

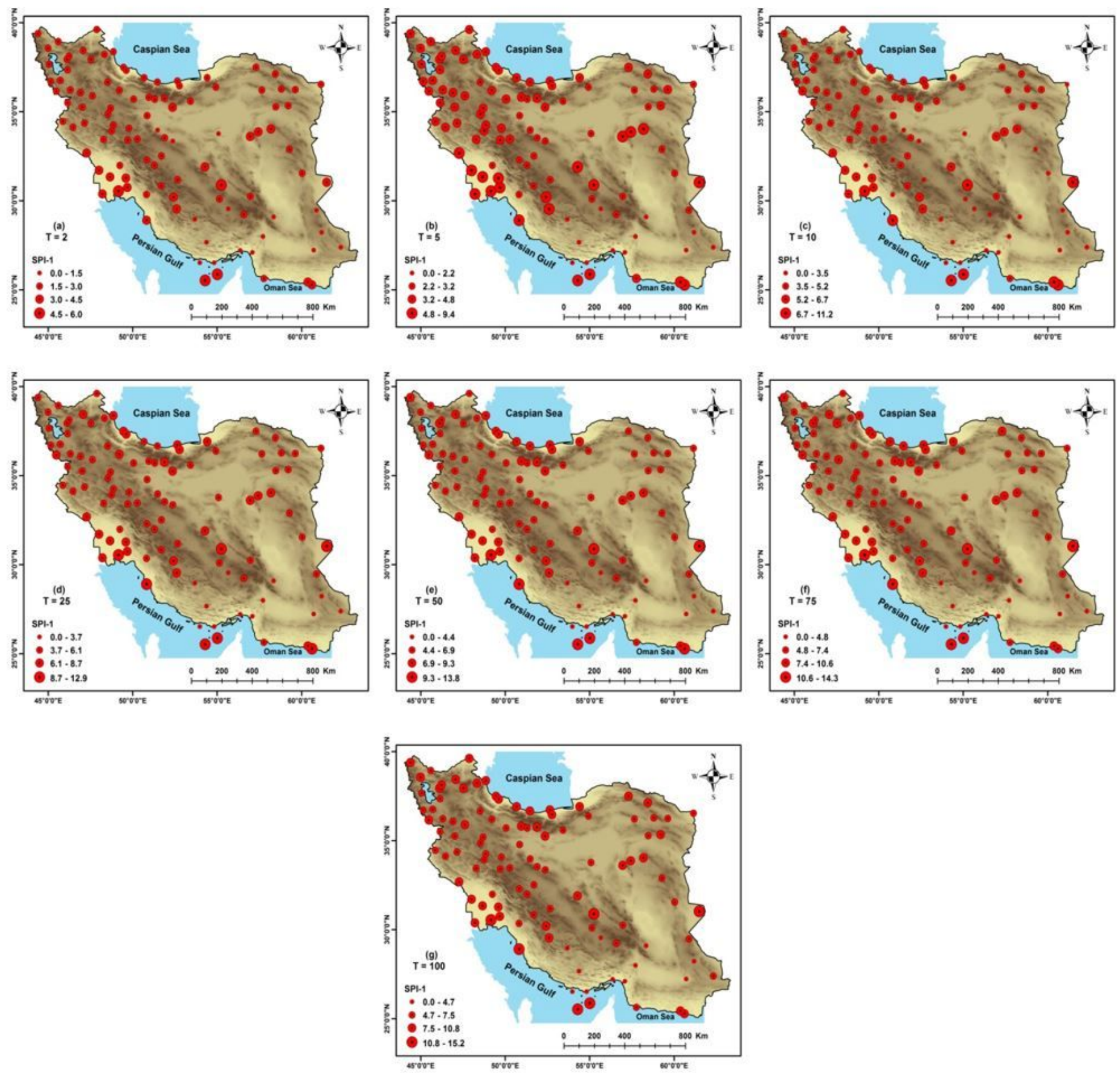

Figure 6

Spatial pattern of drought severity for SPI-1 at return periods (a) $T=2$, (b) $T=5$, (c) $T=10$, (d) $T=25$, (e) $\mathrm{T}=50$, (f) $\mathrm{T}=75$, and $(\mathrm{g}) \mathrm{T}=100$ years 

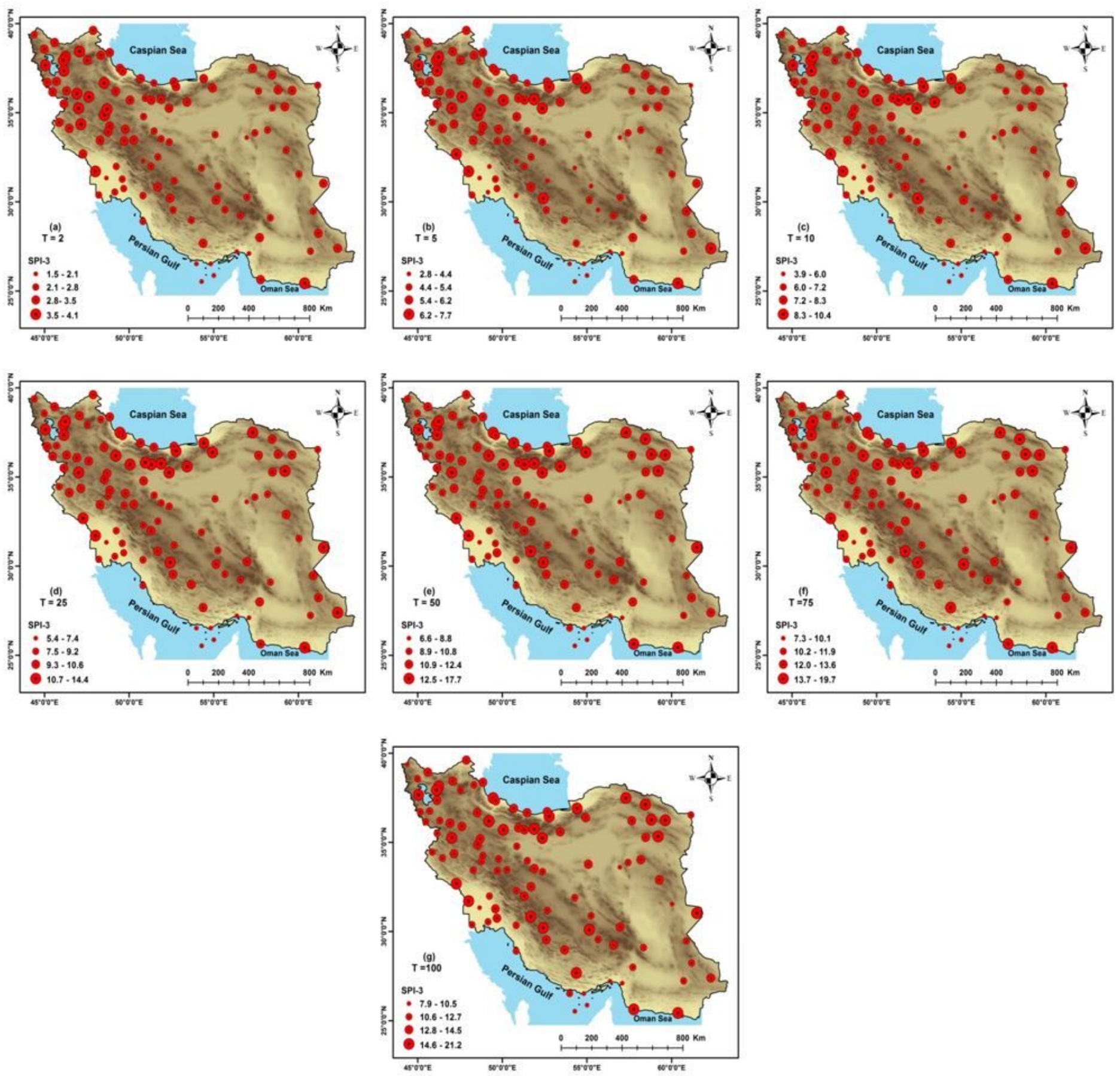

Figure 7

Spatial pattern of drought severity for SPI-3 at return periods (a) $T=2$, (b) $T=5$, (c) $T=10$, (d) $T=25$, (e) $T=50$, (f) $T=75$, and $(g) T=100$ years 

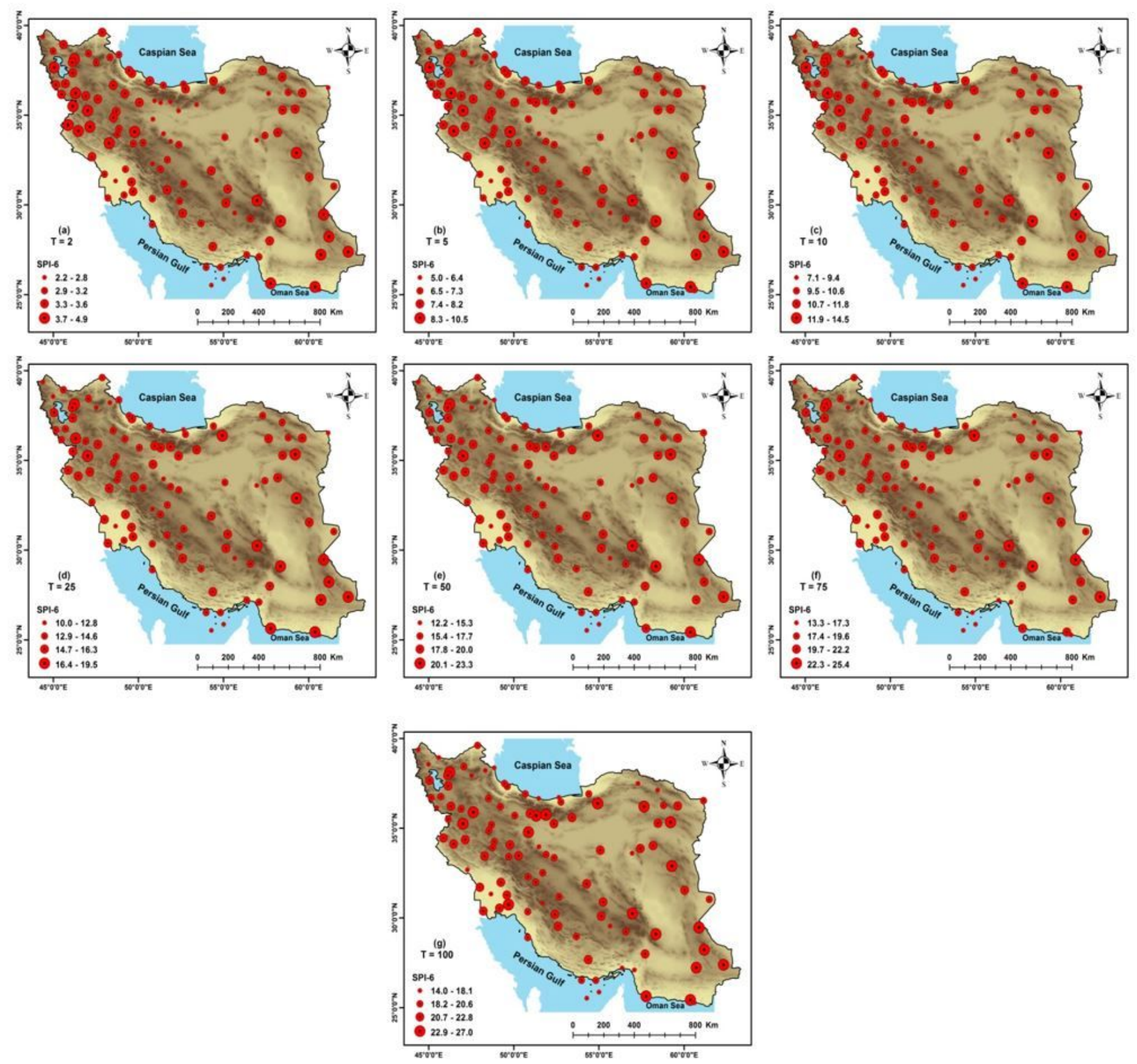

Figure 8

Spatial pattern of drought severity for SPI-6 at return periods (a) $T=2$, (b) $T=5$, (c) $T=10$, (d) $T=25$, (e) $T=50$, (f) $T=75$, and $(g) T=100$ years 

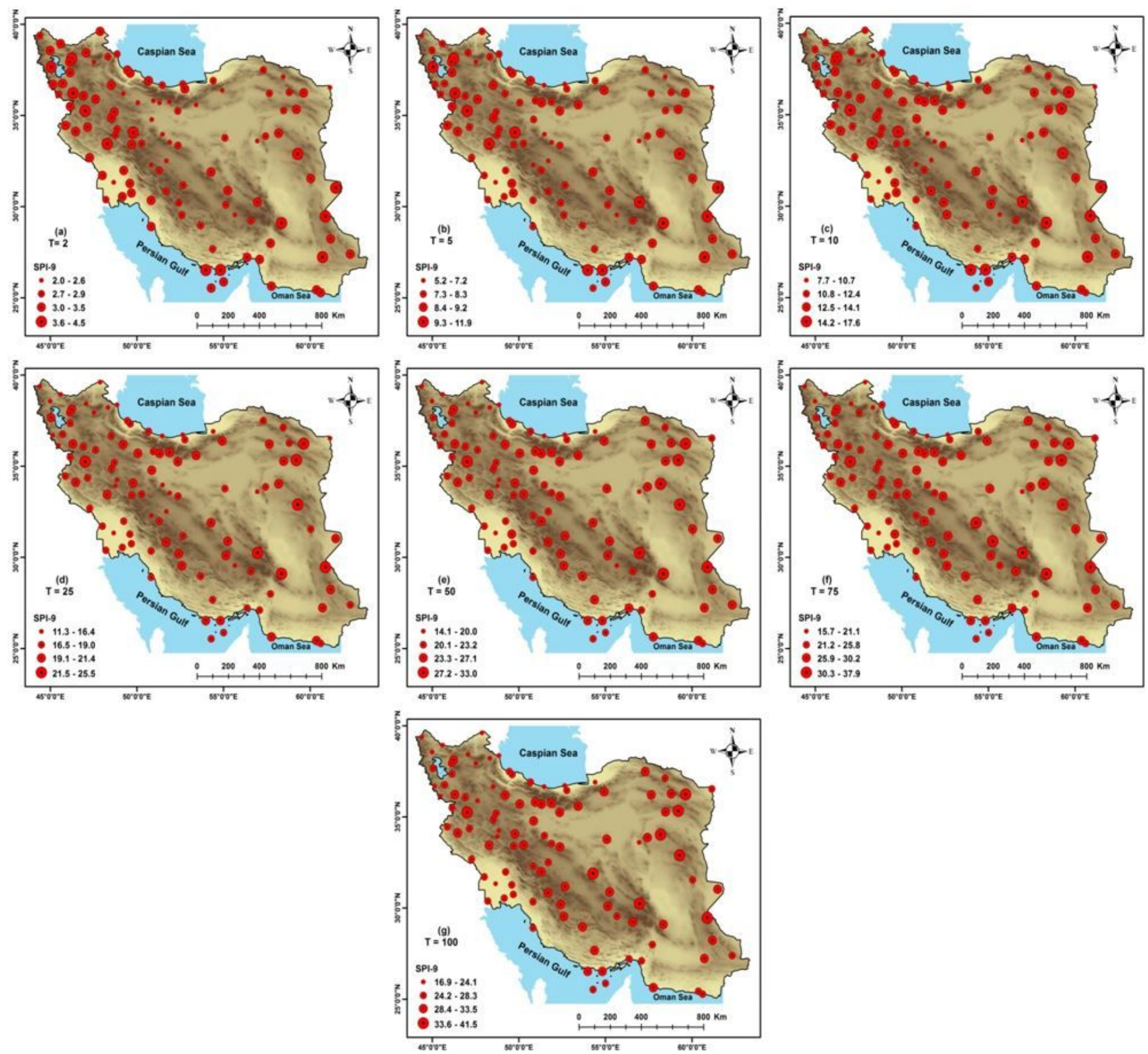

Figure 9

Spatial pattern of drought severity for SPI-9 at return periods (a) $T=2$, (b) $T=5$, (c) $T=10$, (d) $T=25$, (e) $\mathrm{T}=50$, (f) $\mathrm{T}=75$, and $(\mathrm{g}) \mathrm{T}=100$ years 

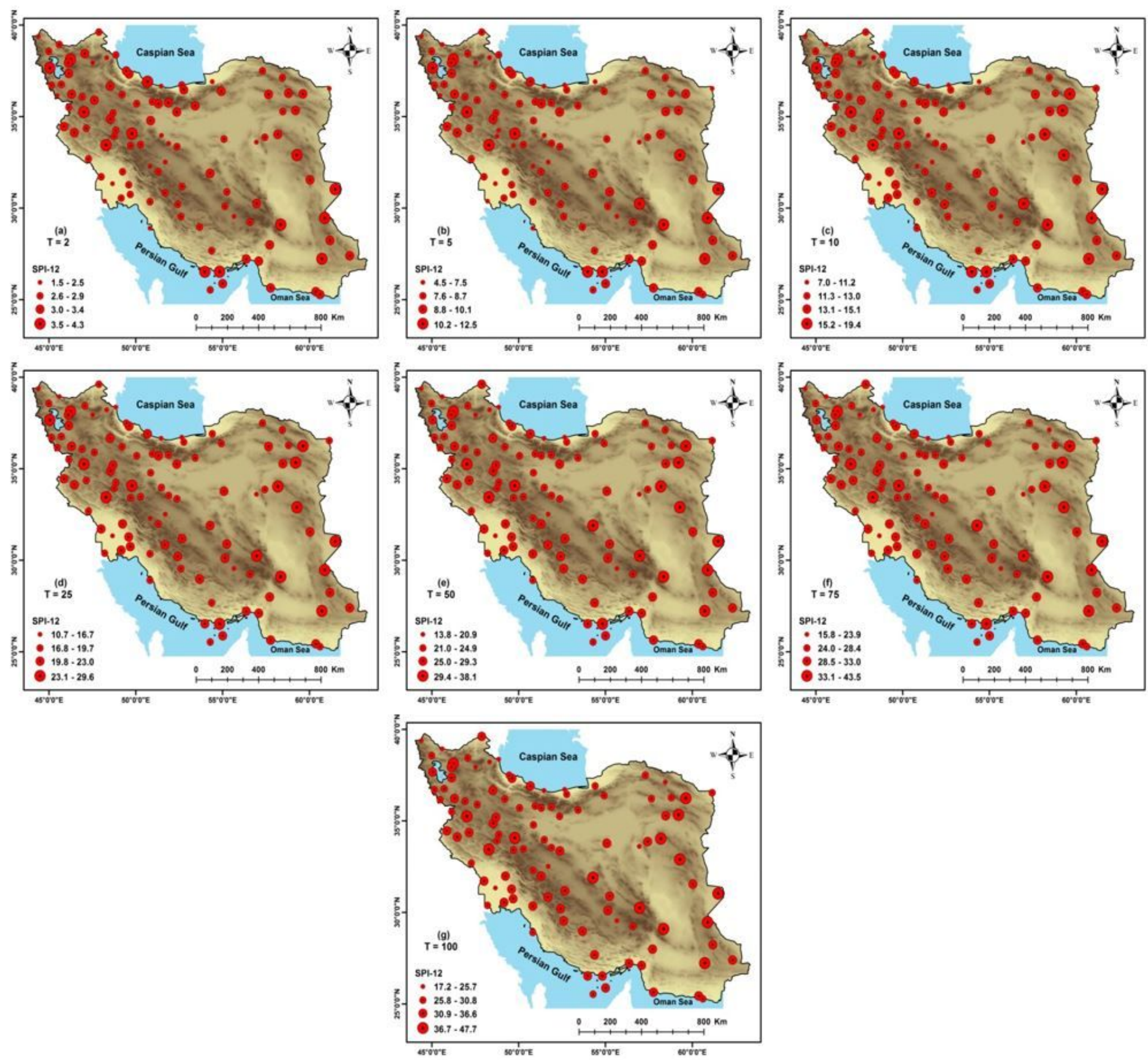

Figure 10

Spatial pattern of drought severity for SPI-12 at return periods (a) $T=2$, (b) $T=5$, (c) $T=10$, (d) $T=25$, (e) $T=50$, (f) $T=75$, and $(g) T=100$ years 

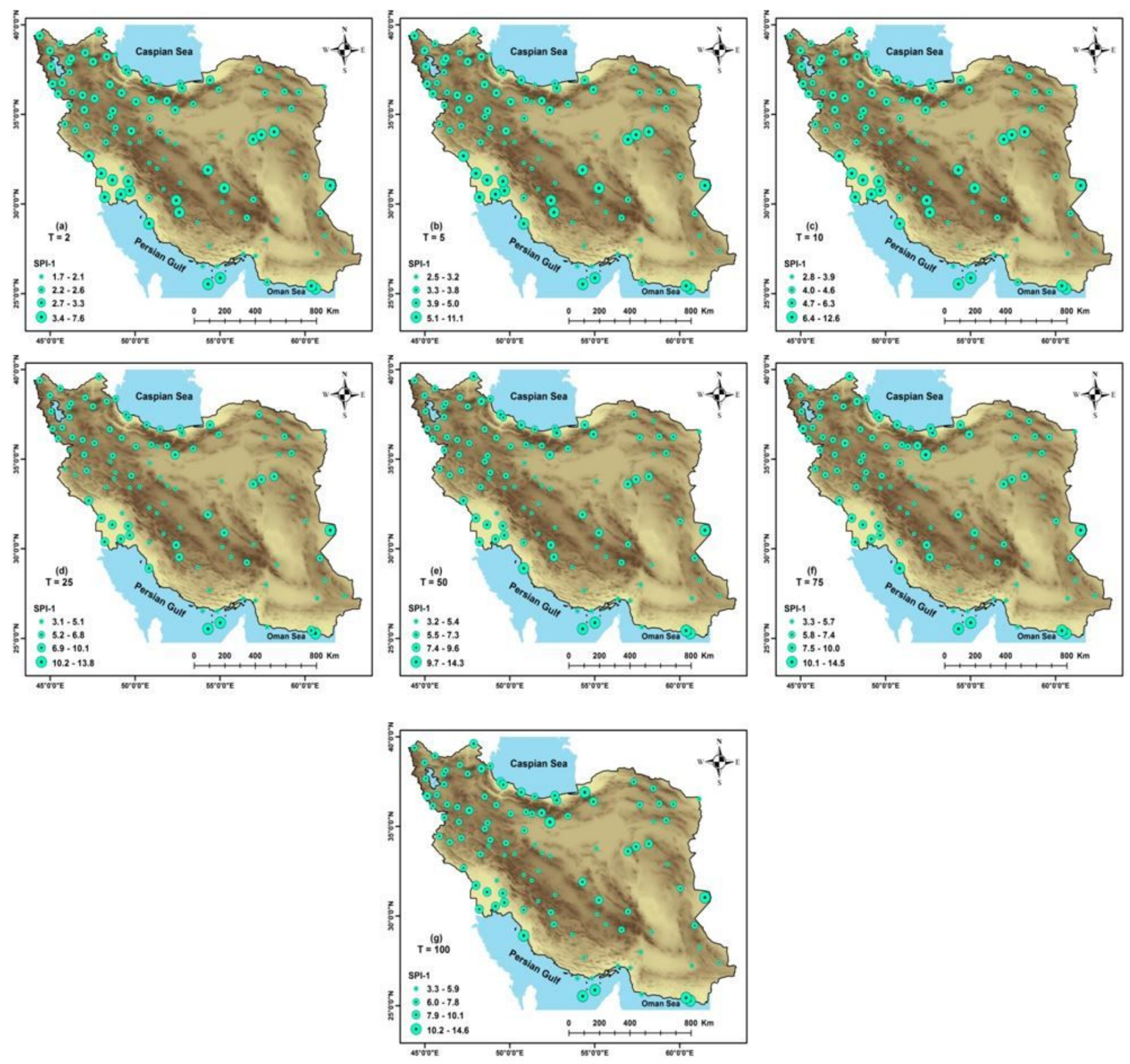

\section{Figure 11}

Spatial pattern of drought duration for SPI-1 at return periods (a) $T=2$, (b) $T=5$, (c) $T=10$, (d) $T=25$, (e) $\mathrm{T}=50$, (f) $\mathrm{T}=75$, and $(\mathrm{g}) \mathrm{T}=100$ years

\section{Figure 12}

Spatial pattern of drought duration for SPI-3 at return periods (a) $T=2$, (b) $T=5$, (c) $T=10$, (d) $T=25$, (e) $\mathrm{T}=50$, (f) $\mathrm{T}=75$, and $(\mathrm{g}) \mathrm{T}=100$ years 

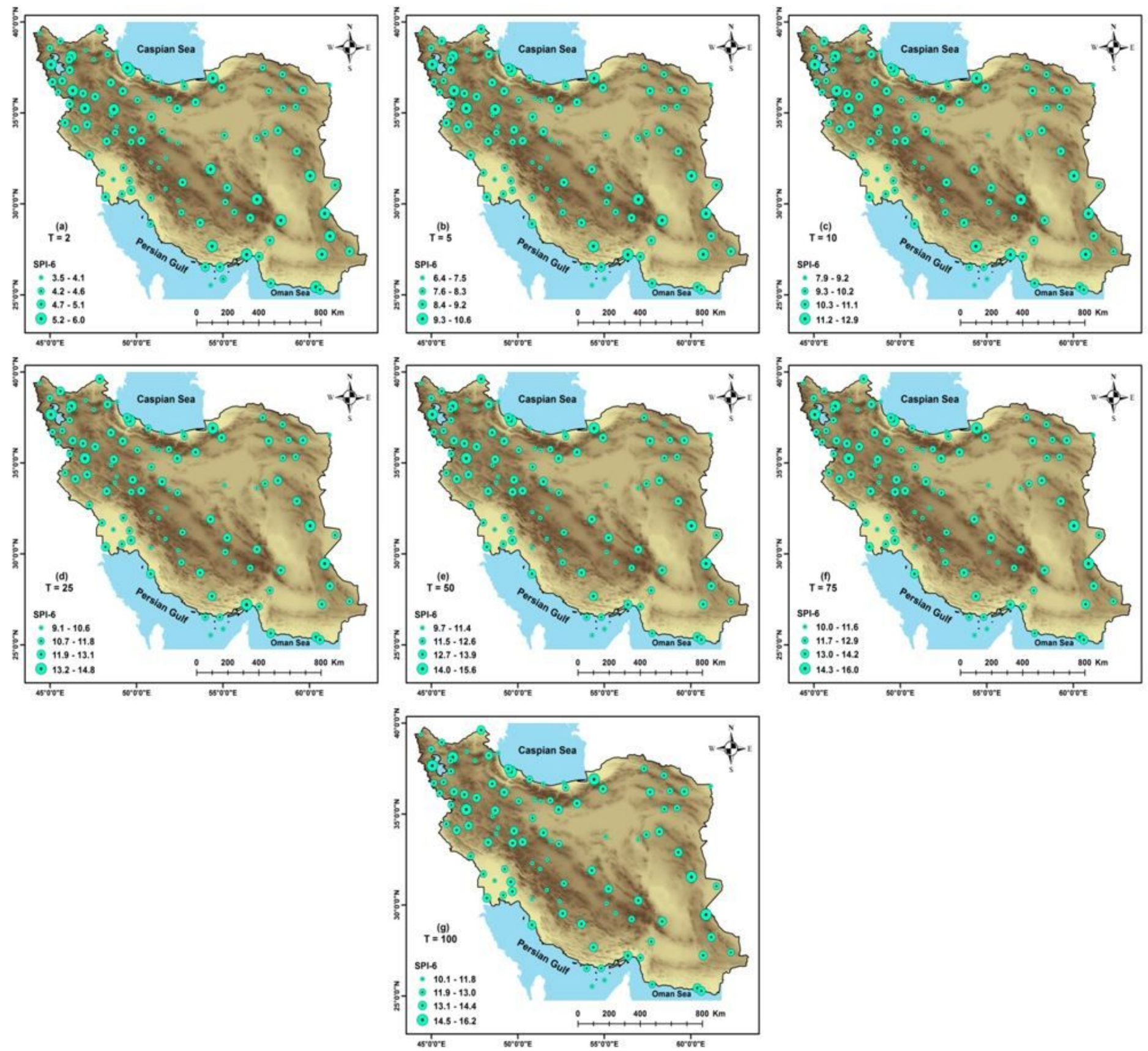

Figure 13

Spatial pattern of drought duration for SPI-6 at return periods (a) $T=2$, (b) $T=5$, (c) $T=10$, (d) $T=25$, (e) $T=50,(f) T=75$, and $(g) T=100$ years 

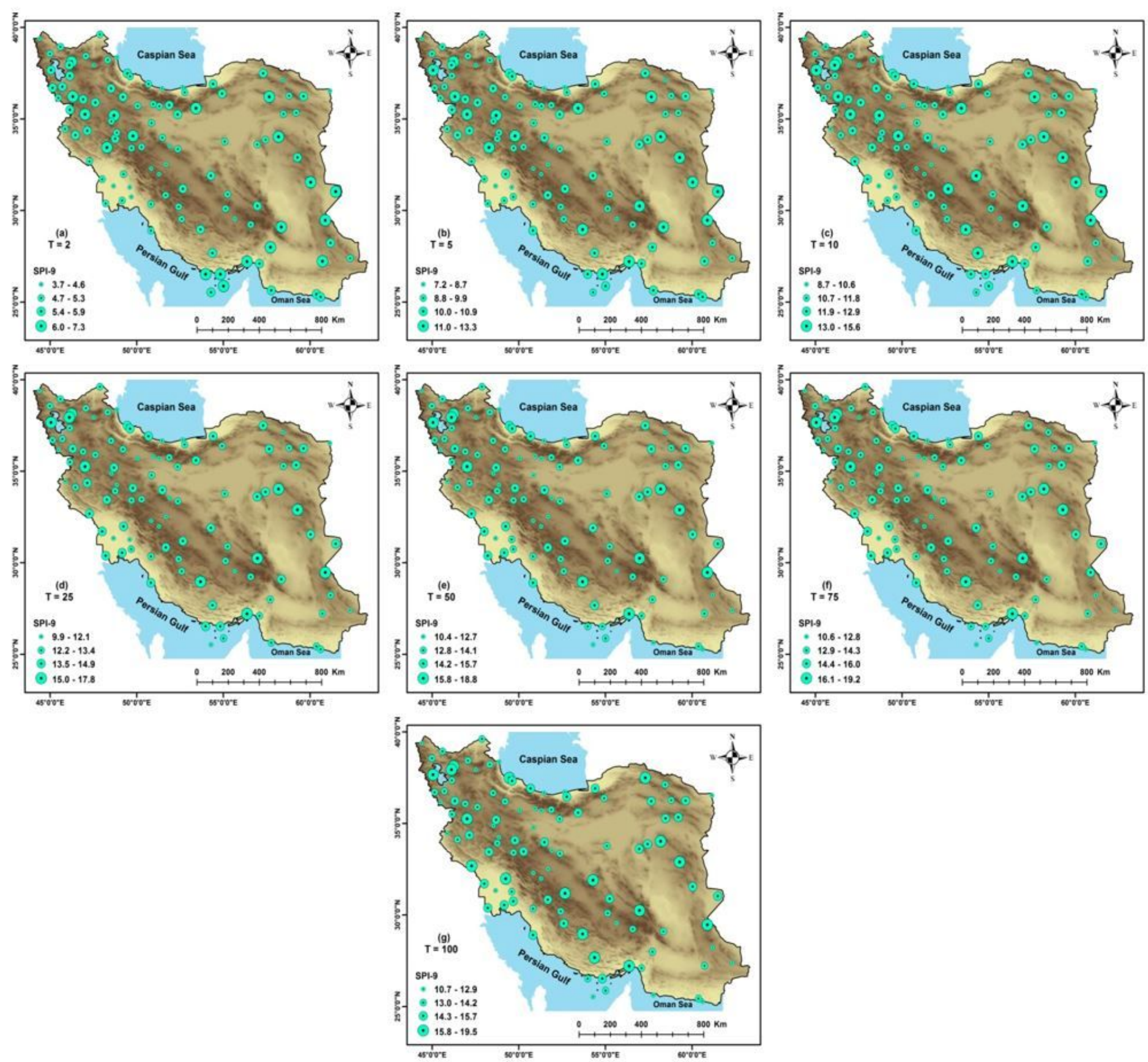

Figure 14

Spatial pattern of drought duration for SPI-9 at return periods (a) $T=2$, (b) $T=5$, (c) $T=10$, (d) $T=25$, (e) $T=50$, (f) $T=75$, and $(g) T=100$ years 

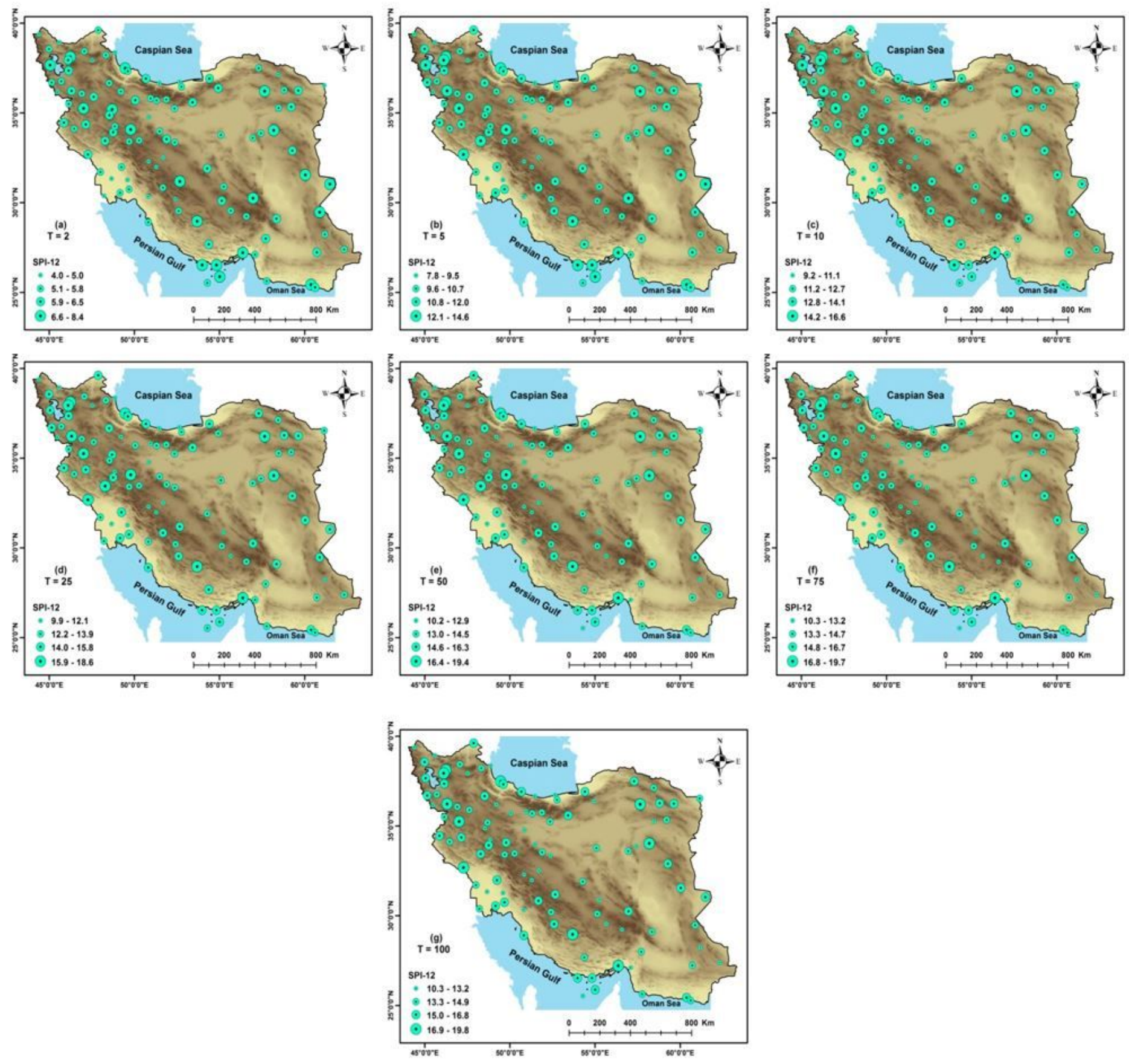

\section{Figure 15}

Spatial pattern of drought duration for SPI-12 at return periods (a) $T=2$, (b) $T=5$, (c) $T=10$, (d) $T=25$, (e) $T=50$, (f) $T=75$, and $(g) T=100$ years 

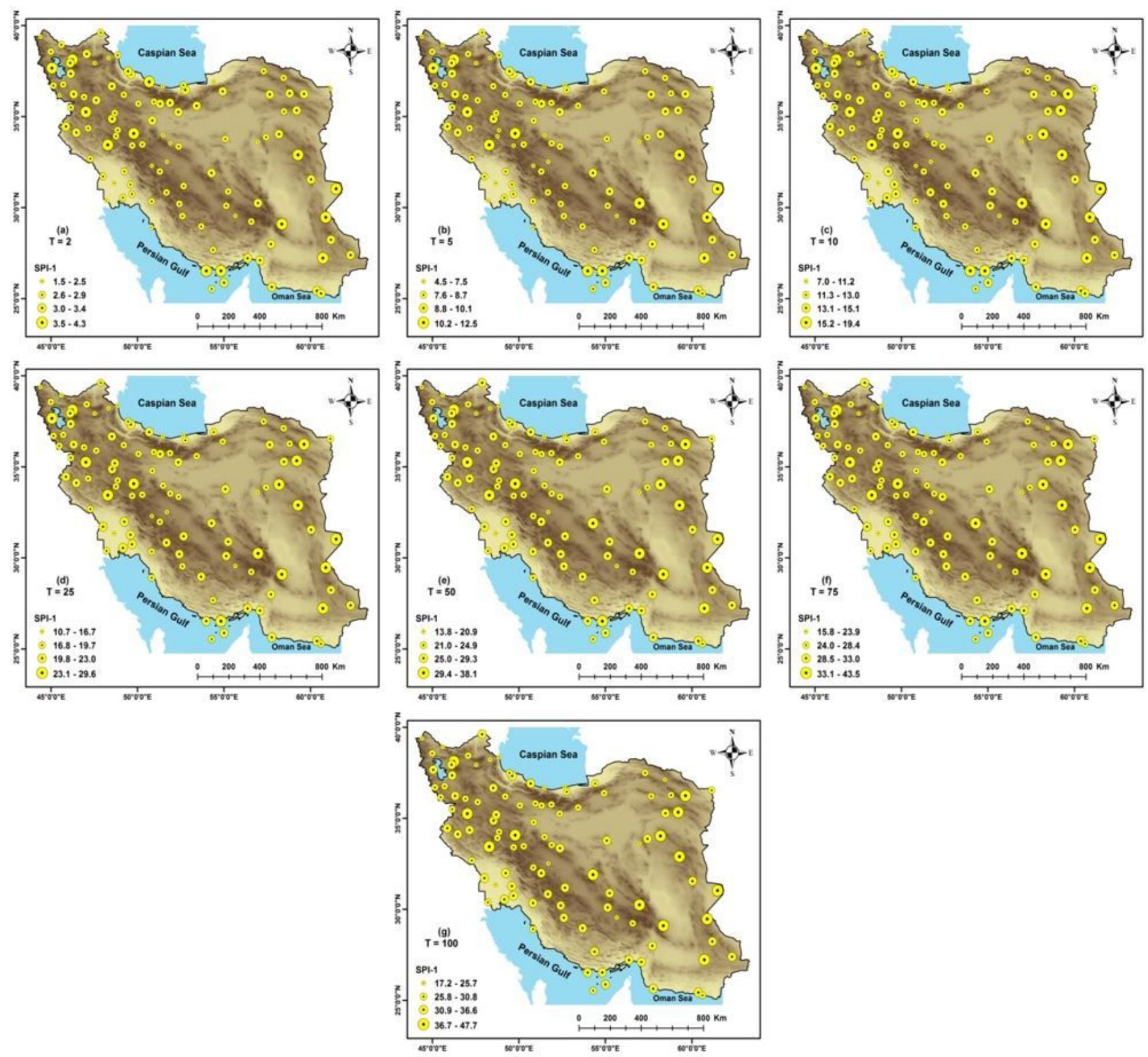

\section{Figure 16}

Spatial pattern of drought magnitude for SPI-1 at return periods (a) $T=2$, (b) $T=5$, (c) $T=10$, (d) $T=25$, (e) $\mathrm{T}=50$, (f) $\mathrm{T}=75$, and $(\mathrm{g}) \mathrm{T}=100$ years

\section{Figure 17}

Spatial pattern of drought magnitude for SPI-3 at return periods (a) $T=2$, (b) $T=5$, (c) $T=10$, (d) $T=25$, (e) $\mathrm{T}=50$, (f) $\mathrm{T}=75$, and $(\mathrm{g}) \mathrm{T}=100$ years 
Spatial pattern of drought magnitude for SPI-6 at return periods (a) $T=2$, (b) $T=5$, (c) $T=10$, (d) $T=25$, (e) $T=50$, (f) $T=75$, and $(g) T=100$ years
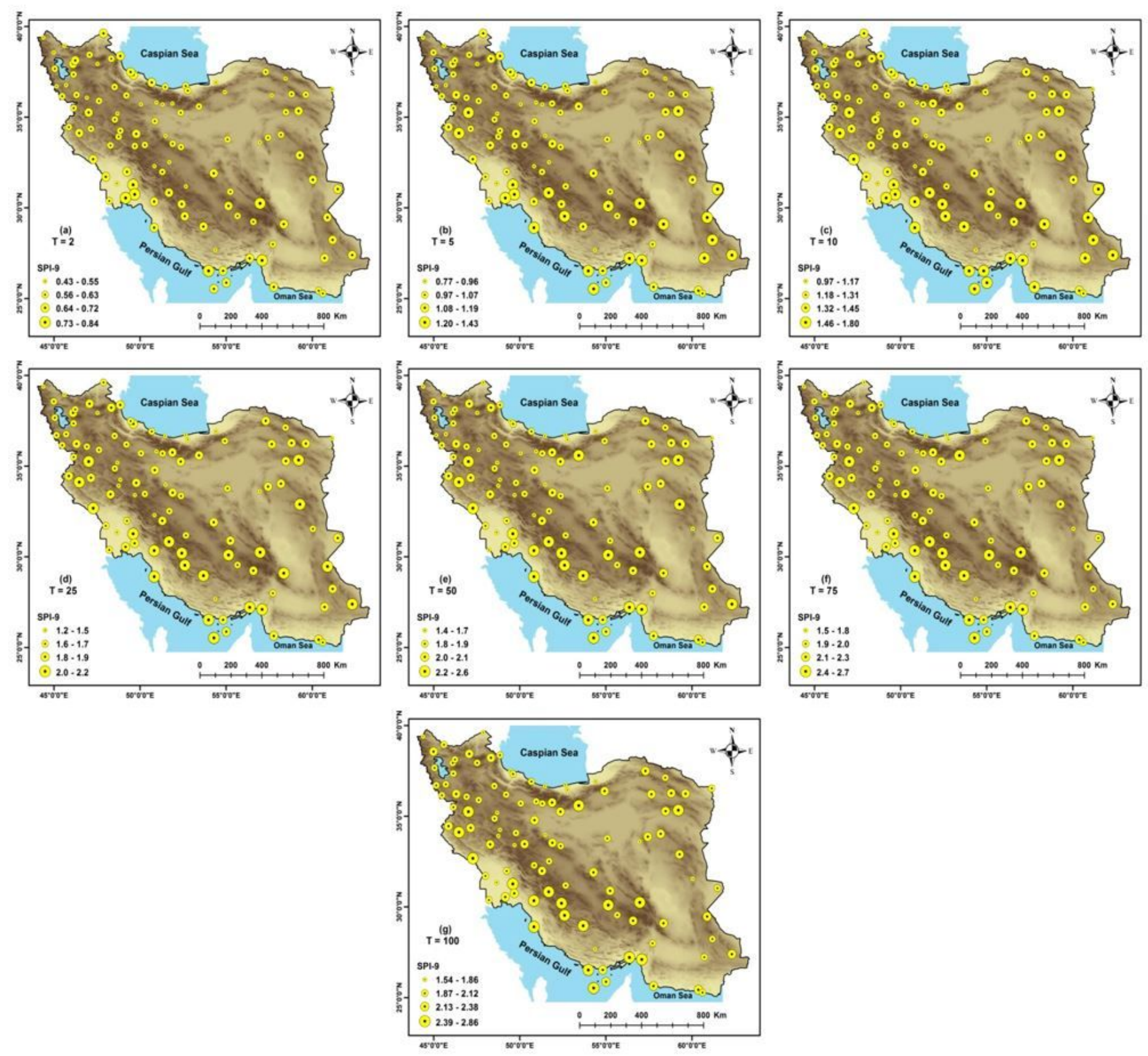

Figure 19

Spatial pattern of drought magnitude for SPI-9 at return periods (a) $T=2$, (b) $T=5$, (c) $T=10$, (d) $T=25$, (e) $T=50$, (f) $T=75$, and $(g) T=100$ years 

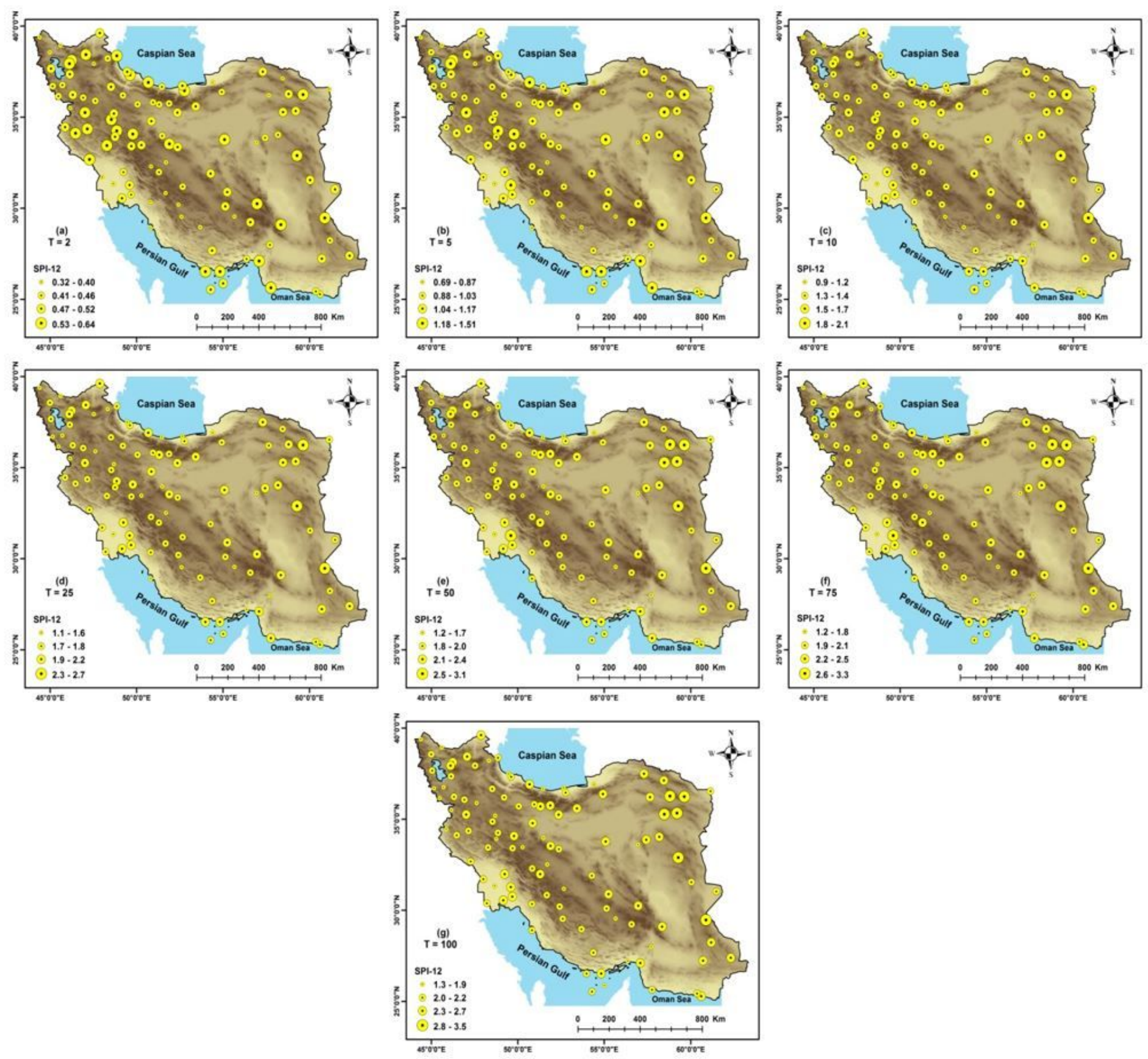

Figure 20

Spatial pattern of drought magnitude for SPI-12 at return periods (a) $T=2$, (b) $T=5$, (c) $T=10$, (d) $T=25$, (e) $T=50$, (f) $T=75$, and $(g) T=100$ years 

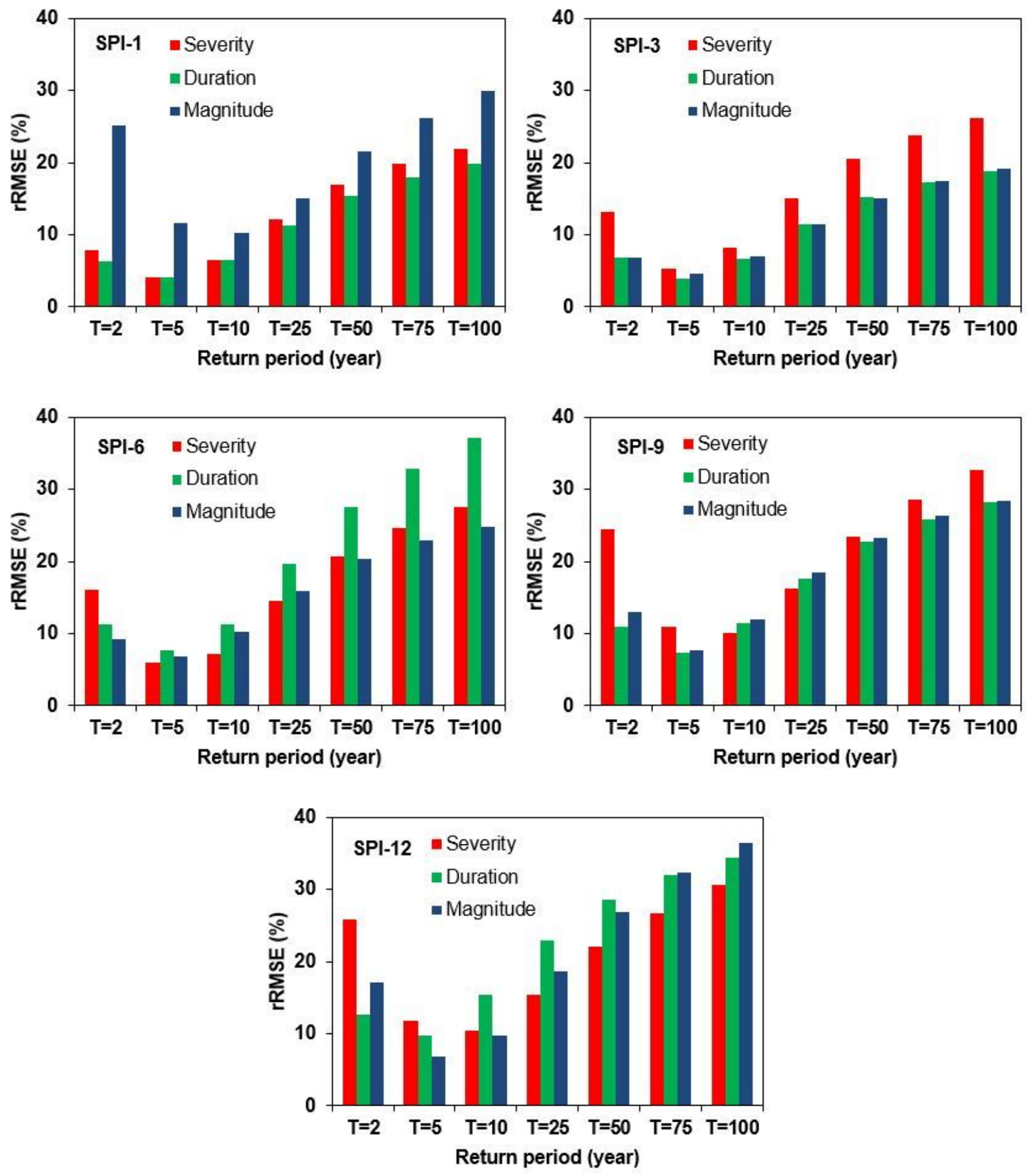

Figure 21

The average rRMSE (\%) of the drought characteristics for SPI-1, $-3,-6,-9$, and -12 at different return periods 